\title{
Survey of Ungulate Abundance on Santa Rosa Island, Channel Islands National Park, California, March 2009
}

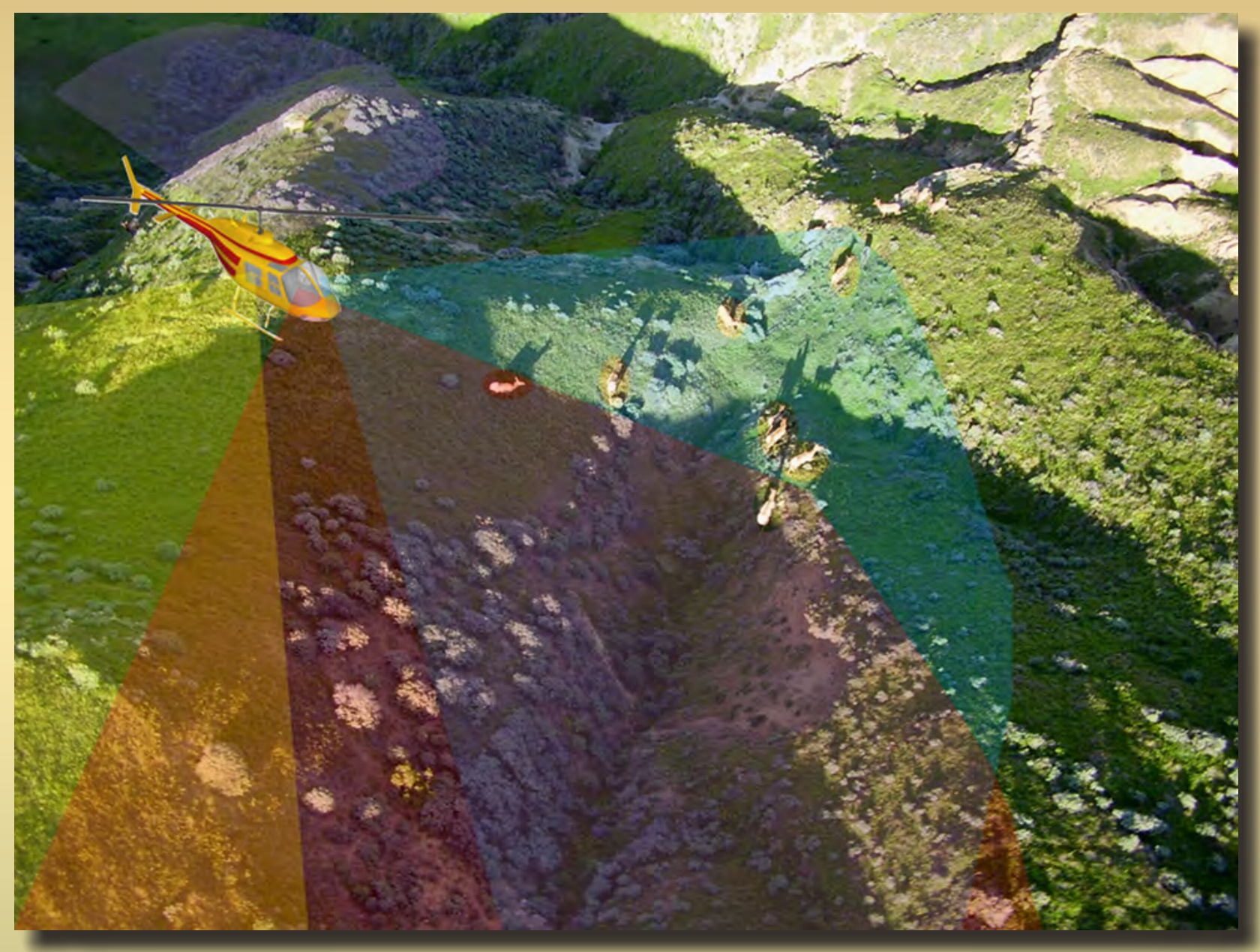

Open-File Report 2009-1243

U.S. Department of the Interior

U.S. Geological Survey 
Cover. Artist's rendering of an aerial survey of free-ranging ungulates. 


\section{Survey of Ungulate Abundance on Santa Rosa Island, Channel Islands National Park, California, March 2009}

By Paul C. Griffin, Kate A. Schoenecker, Peter J.P. Gogan, and Bruce C. Lubow

Open-File Report 2009-1243 


\title{
U.S. Department of the Interior \\ KEN SALAZAR, Secretary \\ U.S. Geological Survey \\ Marcia K. McNutt, Director
}

\section{U.S. Geological Survey, Reston, Virginia: 2009}

\author{
For more information on the USGS — the Federal source for science about the Earth, its natural and living resources, \\ natural hazards, and the environment, visit http://www.usgs.gov or call 1-888-ASK-USGS \\ For an overview of USGS information products, including maps, imagery, and publications, \\ visit http://www.usgs.gov/pubprod \\ To order this and other USGS information products, visit http://store.usgs.gov
}

Any use of trade, product, or firm names is for descriptive purposes only and does not imply endorsement by the U.S. Government.

Although this report is in the public domain, permission must be secured from the individual copyright owners to reproduce any copyrighted materials contained within this report.

Suggested citation:

Griffin, P.C., Schoenecker, K.A., Gogan, P.J.P., and Lubow, B.C., 2009, Survey of ungulate abundance on Santa Rosa Island, Channel Islands National Park, California, March 2009: U.S. Geological Survey Open-File Report 2009-1243, $23 \mathrm{p}$. 


\section{Acknowledgments}

We are grateful to Kate Searle, Colorado State University, for participating in the flights on Santa Rosa Island. We thank the many staff at Channel Islands National Park that helped us in this project, including Sarah Chaney, Angela Guglielmino, Kate Faulkner, Mike Morales, and Rocky Rudolph. For their help during the survey, we thank Sam Spaulding and Tim Vail of Vail \& Vickers Company, and Suzanne Whitney of the Institute for Wildlife Studies. We also thank Katherine Beirne, Olympic National Park geographic information systems (GIS) specialist, for her help with Global Positioning System downloads. We thank Charlie McLaughlin of Aspen Helicopters for his excellent flight skills and for sharing his knowledge of past flight survey routes at Santa Rosa Island.

We thank Kurt Jenkins, U. S. Geological Survey Forest and Rangeland Ecosystem Science Center, for advice on sample design, data analysis, and review of early manuscripts. We thank Tammy Fancher, GIS specialist, U.S. Geological Survey Fort Collins Science Center for her help with Global Positioning System downloads. We are grateful for critical reviews of earlier versions of this report by Steve Hess, U. S. Geological Survey Pacific Island Ecosystem Research Center, and Butch Roelle, U.S. Geological Survey Fort Collins Science Center. 


\section{Contents}

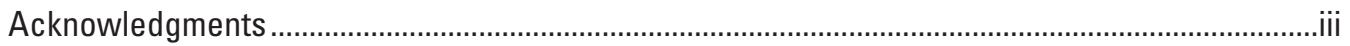

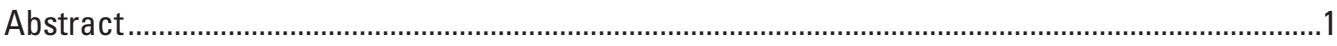

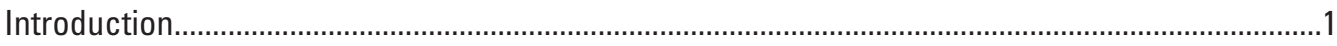

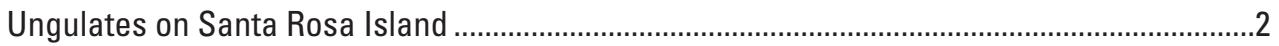

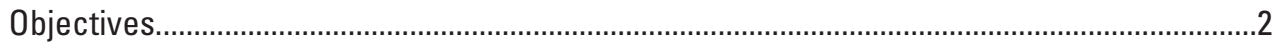

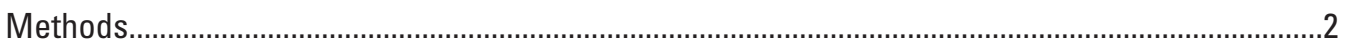

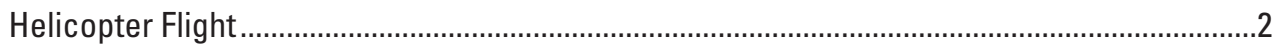

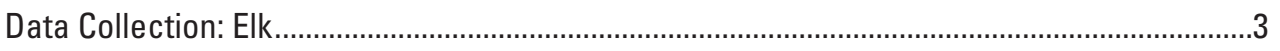

Data Collection: Deer ………………….............................................................................

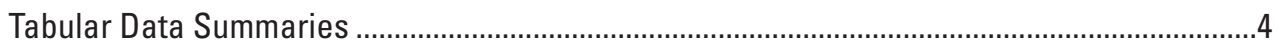

Group-Specific, Double-Observer Correction Factors for Elk .................................................

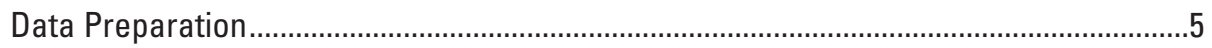

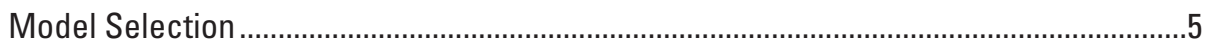

Detection Probability and Abundance Estimation ........................................................

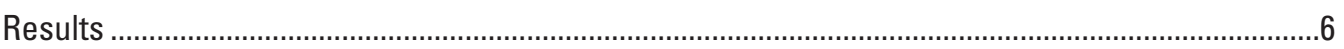

Environmental Conditions, Survey Coverage, and Flight Speed ...............................................

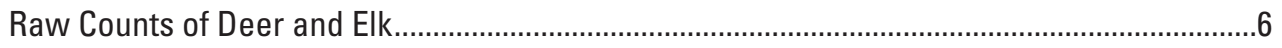

Estimated Abundance of Elk ...............................................................................................

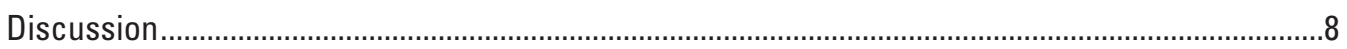

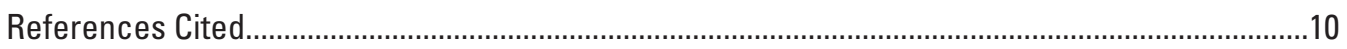

Appendix 1. Replicas of Flight Data Forms Used by Participants in Aerial

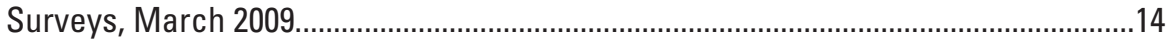

Appendix 2. Modeling Approach 1: Back-Seat Observations Pooled ...................................16

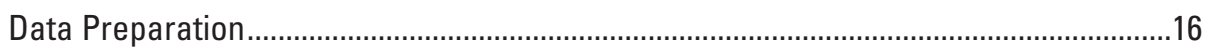

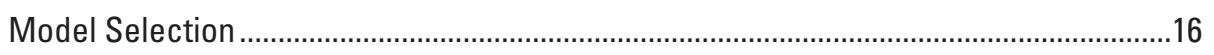

Detection Probability and Abundance Estimation ........................................................16

Estimated Abundance of Elk ..........................................................................................17

Appendix 3. Modeling Approach 2: Separate Detection Probabilities for

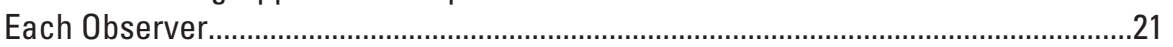

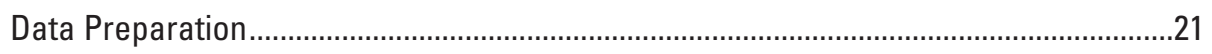

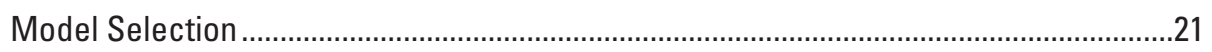

Detection Probability and Abundance Estimation ………............................................22

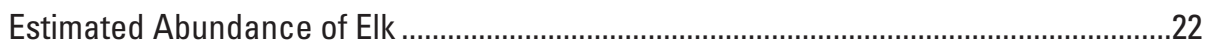

\section{Figures}

1-3. Maps showing:

1. Flight path of three flight segments on March 19, 2009 ..........................................

2. Locations of 81 elk groups (461 elk) observed on Santa Rosa Island on March 19, 2009

3. Locations of 161 deer groups ( 434 deer) observed on Santa Rosa Island on March 19, 2009 


\section{Tables}

1. Flight speed and an index of survey coverage tabulated by zone ....................................

2. Number of observed ungulate groups by survey zone......................................................

A2-1. Table of probabilities estimated in the modeling approach with back-seat observations pooled.

A2-2. List of covariates that were potentially included in the modeling approach with back-seat observations pooled

A2-3. Estimates of the beta ( $\beta$ ) parameters for the logit link function in the highest ranked model for back-seat observations pooled

A2-4. Expected group-specific overall probabilities of detecting an elk group, $\hat{p}_{\text {detect }, i}$, and contributions to total estimates of elk abundance, $\hat{N}_{\text {available }}$, for each observed elk group, based on the top ranked model of the modeling approach with back-seat observers pooled.

A3-1. Model rankings for the analysis that estimated individual observer detection probability

\section{Conversion Factors and Datum}

\begin{tabular}{lcl}
\hline Multiply & By & To obtain \\
\hline \multicolumn{3}{c}{ Length } \\
\hline meter $(\mathrm{m})$ & 3.281 & feet $(\mathrm{ft})$ \\
kilometer $(\mathrm{km})$ & 0.621 & miles $(\mathrm{mi})$ \\
kilometer & 0.540 & miles, nautical $(\mathrm{nmi})$ \\
\hline \multicolumn{3}{c}{ Area } \\
\hline square kilometer $\left(\mathrm{km}^{2}\right)$ & 0.386 & square miles $\left(\mathrm{mi}^{2}\right)$ \\
\hline & Speed & \\
\hline kilometers per hour $(\mathrm{km} / \mathrm{hr})$ & 0.621 & miles per hour $(\mathrm{mi} / \mathrm{hr})$ \\
\hline
\end{tabular}

Temperature in degrees Celsius $\left({ }^{\circ} \mathrm{C}\right)$ may be converted to degrees Fahrenheit $\left({ }^{\circ} \mathrm{F}\right)$ as follows:

$$
{ }^{\circ} \mathrm{F}=\left(1.8 x^{\circ} \mathrm{C}\right)+32
$$

Horizontal coordinate information in this report is referenced to the North American Datum of 1927 (NAD 27), zone 10. Some spatial data layers that are associated with this project were recorded in NAD 83 or WGS 84 coordinate systems, with transformations performed in a geographic information system. 



\title{
Survey of Ungulate Abundance on Santa Rosa Island, Channel Islands National Park, California, March 2009
}

\author{
By Paul C. Griffin', Kate A. Schoenecker', Peter J.P. Gogan', and Bruce C. Lubow ${ }^{2}$
}

\section{Abstract}

Reliable estimates of elk (Cervus elaphus) and deer (Odocoileus hemionus) abundance on Santa Rosa Island, Channel Islands National Park, California, are required to assess the success of management actions directed at these species. We conducted a double-observer aerial survey of elk on a large portion of Santa Rosa Island on March 19, 2009. All four persons on the helicopter were treated as observers. We used two analytical approaches: (1) with three capture occasions corresponding to three possible observers, pooling the observations from the two rear-seat observers, and (2) with four capture occasions treating each observer separately. Approach 1 resulted in an estimate of 483 elk in the survey zone with a 95-percent confidence interval of 479 to 524 elk. Approach 2 resulted in an estimate of 489 elk in the survey zone with a 95-percent confidence interval of 471 to 535 elk. Approximately 5 percent of the elk groups that were estimated to have been present in the survey area were not seen by any observer. Fog prevented us from collecting double-observer observations for deer as intended on March 20. However, we did count 434 deer during the double-observer counts of elk on March 19. Both the calculated number of elk and the observed number of deer are minimal estimates of numbers of each ungulate species on Santa Rosa Island as weather conditions precluded us from surveying the entire island.

\section{Introduction}

It is widely acknowledged that aerial surveys to assess the abundance of free-ranging ungulates typically do not detect all of the animals present (Caughley, 1974). In mathematical terms, the probability of detecting an animal or animal group is unknown, but less than 1.0, so that the number of animals counted is less than the true number present (Seber, 1982). Suites of methods attempt to estimate detection probabilities because the total population size of animals can be estimated if the number seen and the detection probability are

\footnotetext{
${ }^{1}$ U.S. Geological Survey.
}

${ }^{2}$ Colorado State University. known (Otis and others, 1978; Buckland and others, 2004; MacKenzie and others, 2006).

In aerial surveys of free ranging-ungulates, detection bias results when observers fail to detect all the groups of animals that are available to be seen within the surveyed area. There are several approaches to estimating detection bias in aerial surveys. In one approach, a sightability function to estimate detection probability is developed based on the known presence of marked animals (Samuel and others, 1987). The resulting sightability correction factor allows for an estimate of those animals present but not seen. Detection probabilities have also been estimated, however, in situations where no marked animals were present by using a double-observer method of observation. Taxa for which double-observer methods have been used include amphibians (Campbell Grant and others, 2005), birds (Caughley and Grice, 1982; Evans Mack and others, 2002), marine mammals (Pollock and others, 2006), ursids (Crête and others, 1991), and a variety of ungulates including equids (Graham and Bell, 1989; Lubow and Ransom, 2007), and bison (Bison bison) and elk (Cervus elaphus, Schoenecker and others, 2006). The double-observer method is intended to estimate the probability that neither observer saw a given animal or animal group and is based on the assumption that two observers searching the same survey area have independent probabilities of detecting an animal (Barker, 2008).

Ideally, the double-observer method requires that animals within a surveyed area be fitted with radio collars for the development period to later test whether the observers really were independent and to know what proportion of animals were not detected by either observer (Schoenecker and others, 2006). If a dataset includes sightability trial data for animals within a survey area that did include radio-collared animals, then the detection probability being estimated accounts for groups that were in the survey frame but were not seen by any observer. This would be the standard dataset for development of a sightability model (Samuel and others, 1987; McCorquodale, 2001), where the goal is to estimate the probability of detection for all animals in the surveyed area. Sightability models based on animals detected by using radio telemetry can account for animals that had a probability of detection of zero; for example, groups under such dense cover that detecting them without using radio telemetry is impossible. 
If, however, a dataset does not include telemetry data, but only includes animal groups that were seen by independent observers, then one can only estimate the probability of one or another of two observers having seen a group (Marsh and Sinclair, 1989; Crête and others, 1991). Thus, if behavior or cover causes some fraction of the surveyed population to have a probability of detection of zero, a double-observer correction factor based on sampling without radio telemetry will still yield an underestimate of the total number of animals present.

Heterogeneity in detection probability is an important source of bias because using a single estimate for group detection probabilities will tend to underestimate total abundance and its associated variance. Some heterogeneity in detection probability can be modeled by including the effects of covariates such as group size, animal behavior, or vegetative cover (Samuel and others, 1987; Otten and others, 1993; Unsworth and others, 1994; Thompson and others, 1998; Cogan and Diefenbach, 1998; McCorquodale, 2001; Schoenecker and others, 2006; Lubow and Ransom, 2007). Unmodeled heterogeneity will tend to lead to overestimates of detection probability and a corresponding underestimate of abundance and its associated variance (Borchers and others, 2006), although any bias caused by heterogeneity will necessarily decrease as the overall probability of detection approaches 1.0.

\section{Ungulates on Santa Rosa Island}

Santa Rosa Island has been part of Channel Islands National Park since 1980, and the land was purchased from the Vail \& Vickers Company by the National Park Service (NPS) in 1986. The nonnative, privately owned elk and deer (Odocoileus hemionus) have an adverse impact on a number of endemic plants, including eight federally listed plant species (U.S. Fish and Wildlife Service, 2000), and preclude the recovery of unique island plant communities. A courtsanctioned settlement agreement requires a phased reduction of deer and elk numbers from 2008 through removal of all cervids from Santa Rosa Island by the end of December 2011. The settlement agreement has a mandated maximum number of animals of each species that are permitted to be present on the island each December. The National Park Service is required to determine the number of deer and elk on the island and to ensure that numbers do not exceed the limits specified in the settlement agreement. Elk and deer have been counted annually by the animals' owner, Vail \& Vickers, and the NPS as part of the settlement agreement.

Surveys conducted prior to 2008 enumerated deer and elk on Santa Rosa Island, but no previous work has attempted to assess the detection probability of either species on Santa Rosa Island. In past counts (Timothy Vail, written commun., 2008) three observers in a helicopter cooperate to develop a single estimate of elk and deer numbers. The reported standard deviations around the mean were not uncertainty estimates for the population of ungulates; rather, they reflected miscommunications between observers in the number of animals seen.
Thus, no population correction factor has previously been estimated or applied to deer and elk counts on this island.

On March 19, 2009, we conducted aerial surveys of elk and deer on Santa Rosa Island. The surveys were similar to those done in the past, except that deer and elk groups were both noted, and more detailed data were recorded for elk groups. We did not survey a small fraction of the island that was obscured by fog.

We used a subset of the elk group dataset to estimate detection probabilities for the elk group by using a doubleobserver analytical approach. The Santa Rosa Island elk herd included no marked animals, so the correction factor that we developed from a double-observer analysis only accounts for animals that were potentially visible; it does not account for animals that were effectively invisible because of behavior, extremely dense hiding cover, or location in an area that was not surveyed.

\section{Objectives}

The objectives of this study were to:

1. Count the number of deer and elk seen during helicopter surveys over Santa Rosa Island.

2. Tabulate these counts within pre-existing survey zones.

3. Estimate the expected group-specific probability of detection for elk groups and use these probabilities to estimate the total number of elk that were in the surveyed area.

\section{Methods}

\section{Helicopter Flight}

This report presents results of data collected by aerial survey on March 19, 2009, and associated analyses. We collected count data for deer and elk but were unable to collect the data necessary to meet objective 3 for elk. Fog prevented us from conducting the second planned day of survey, which would have been primarily devoted to collecting the data necessary to meet objective 3 for deer.

We followed a flight safety plan that was developed specifically for this mission (Kate Schoenecker, unpub. data, 2009). The pilot (C. McLaughlin, Aspen Helicopters) and two U.S. Geological Survey (USGS) observers (K. Schoenecker, P. Griffin), and a Colorado State University (CSU) observer (K. Searle) flew in a Bell LongRanger helicopter with doors removed to increase observers' views. The boundaries of eight elk and deer survey zones that were used during the joint collection of total counts by Vail \&Vickers and NPS (fig. 1) are from a NPS-digitized version of a map provided to the USGS by Timothy Vail in 2007. Survey zone boundaries were visible on the pilot's Global Positioning System (GPS) 


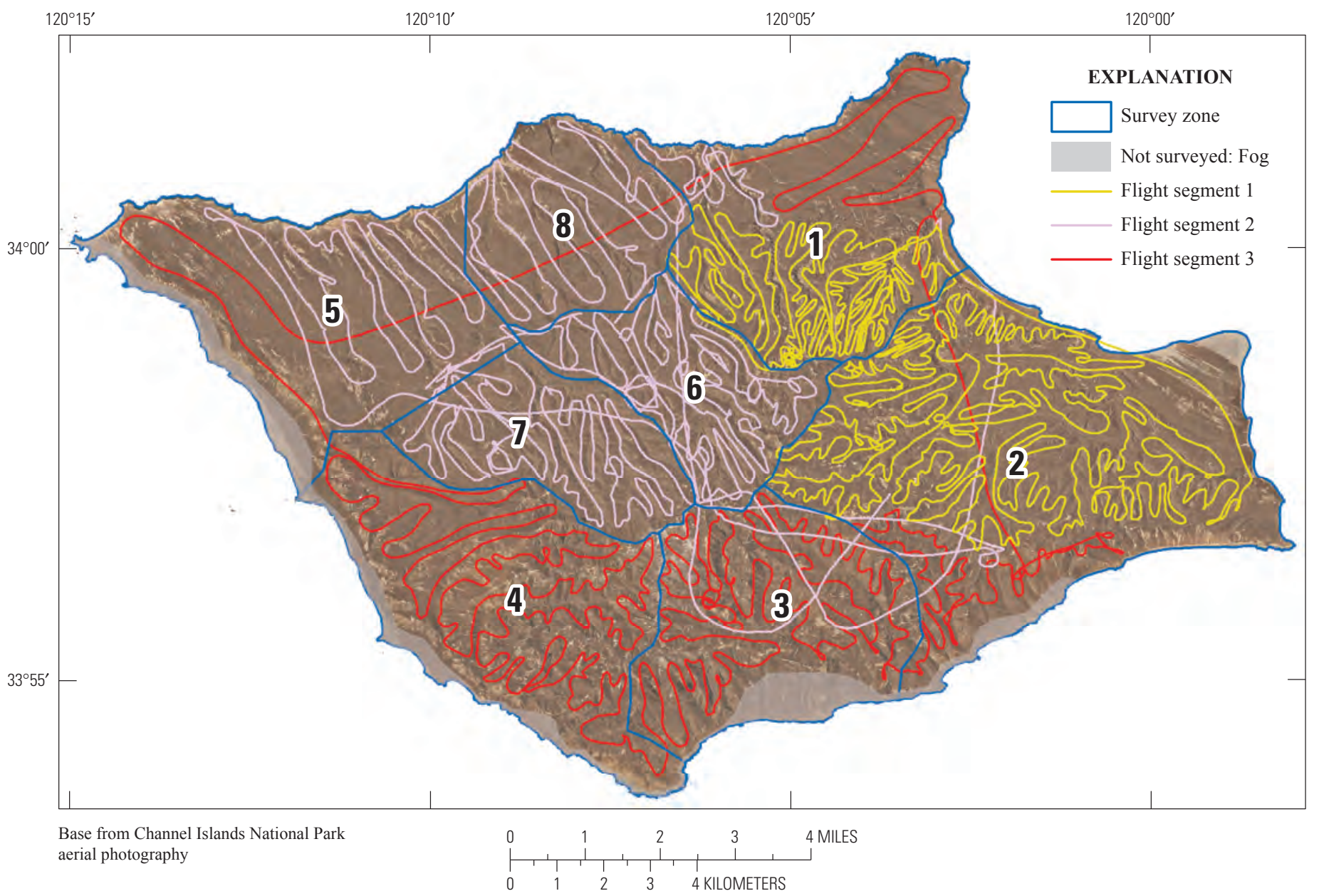

Figure 1. Flight path of three flight segments on March 19, 2009. The first flight segment included partial survey of zones 1 and 2; 101 elk and 120 deer were seen. The second flight segment included survey of zones 6, 7, and 8, and partial surveys of zones 1 and 5 ; 191 elk and 142 deer were seen. The third flight segment included a survey of zones 3 and 4 and partial surveys of zones 2, 5, and 1; 169 elk and 172 deer were seen. Areas with fog along the western and southern margin of the island were not surveyed.

unit. The pilot indicated that the flight pattern and speeds approximately followed those of previous surveys.

The helicopter flight path for each of three flight segments was recorded with GPS units, which recorded points at intervals of 5 seconds (s) (USGS) or about $8 \mathrm{~s}$ (Aspen Helicopter). Here, a segment is a stretch of the flight path between refueling events. For mapping, we used points that were collected at 5-s intervals by a Thales MobileMapper GPS unit on the first and third segments and points recorded approximately every $8 \mathrm{~s}$ by the helicopter's Garmin 396 GPS unit on the second segment. The flight-path points formed the basis for analysis of flight path length, flight speed, and related metrics in ArcMap (ESRI, 2008).

\section{Data Collection: Elk}

For elk only, we collected data with a double-observer method, such that we could select and parameterize a model for group-specific detection probability. We used expected values of group-specific detection probability to estimate the total number of elk that were within the survey area on March 19, 2009.

Observers searched independently for groups of elk within their view. In addition to the pilot, who primarily was concerned with safe flight operations, there was a USGS observer seated in the front left of the aircraft and a USGS and CSU observer seated in the rear seats. For both deer and elk, 
a "group" was considered to be one or more individuals. The simultaneous double count method is a form of mark-resight procedure where the front seat is considered one independent survey (the "mark"), and the rear seat acts as a second independent survey (the "resight"). Therefore, no communication about elk groups, visual or verbal, was permitted or occurred between front and rear observers until after both observers had adequate opportunity to detect each elk group independently. The pilot could nonverbally indicate to the left front observer if he saw an elk group so that the rear observers would not be alerted, but alerts would only be made at a time that it would not prevent the left front-seat observer from having an independent opportunity to see the elk group; however, after the group had passed abeam of the helicopter, any observers could notify the entire crew. If the helicopter circled the group to determine group size, then all crew members participated in that count. We noted on the data forms if a front-seat observer spoke out about an elk group before the rear-seat observers had a chance to detect it. We recorded which side of the helicopter was closest to the elk group, as this factor might have influenced the sighting probability for the pilot and left front-seat observer. We also recorded if the helicopter flew only directly over the elk group (for example, the elk were directly along the centerline of the flight path), as this position would have prevented rear-seat observers from seeing the group. To collect data that allowed for testing of individual observer acuity, the USGS and CSU rear-seat observers traded seats after the first flight segment.

Observers that saw a group recorded covariates that could affect detection probability. In addition to group size, covariates were as follows: substrate on which the group was located, vegetation type, vegetation cover, the height of that vegetation, and whether the group was moving or not moving when first spotted. All of these covariates could influence the probability of detecting a given group of animals. An example data sheet is shown in appendix 1 .

We marked as a waypoint the approximate location of each elk group with a Garmin GPSMap 76 handheld GPS unit, at a time when the helicopter was close to that group. To prevent the possibility that any elk group would be counted twice, we referred to these waypoints as well as records of group size and composition if there was ever any question about whether an elk group had been seen before.

\section{Data Collection: Deer}

Fog prevented us from making the second day of survey that had been set aside for recording deer groups with the double-observer method, so we were unable to model detection probabilities for deer. Throughout this report, the number of deer groups and total number of individual deer presented are based only on raw counts, with no application of detection probabilities to correct for likely undercounting.

We recorded all the deer groups that were observed during the March 19, 2009, flights by using an Olympus DS-30 digital voice recorder plugged into the helicopter's avionics system with a CellSet 5000 adapter (Kennedy Technology Group, Inc., Rose Hill, Kansas). As soon as any observer saw a deer group, that observer notified the other crew members, also noting the number of individuals in the group. Crew members made efforts to distinguish deer groups so that any single deer groups would not be counted twice. We did not record data for observed deer groups on paper during flights but instead relied on digital voice recordings of the entire cockpit conversation to capture information about deer groups that were seen. We later listened to all recordings and transcribed the spoken information about deer groups to paper data sheets, recording the exact time when each group was noted and the number of animals in the group.

We took the following measures to reduce or eliminate the chance that any deer group observed was included twice in the total tally of animals. Using the GPS record of the flight path, we transcribed the location of deer groups based on the digital recording. Deer group observations that were located close to each other were only included once in the total count, unless the crew-member conversation clearly indicated that the groups were distinct, based on their location in valleys versus on ridgetops. The location of a deer group was actually the helicopter's location corresponding to the time that each deer group was noted on the voice recording and based on the GPS points closest to that audio recording time. Some deer groups were noted on the audio at times exactly corresponding to a GPS point from the flight path. Other deer groups were noted on the audio recording at times between two GPS points. In such instances, the helicopter's location above these deer groups was interpolated from the line segment between the two closest points. We did this by approximating the fraction of the line-segment length corresponding to the time stamp when the deer group was noted and the number of seconds between the closest GPS points of the flight path. We used the Get Coordinates Tool (Beyer, 2006) in GIS to reveal the NAD27 coordinate for each deer group location.

\section{Tabular Data Summaries}

We used survey zone to organize descriptive aspects of the flight path, such as survey duration and flight-path length. We assessed the survey effort in terms of minutes of survey time per square kilometer of surveyed area (P.J. Gogan, unpub. data) and also in terms of kilometers of flight path traveled per square kilometer of surveyed area. In keeping with past survey methods (P.J. Gogan, unpub. data), we tabulated elk and deer observations according to survey zone. 


\section{Group-Specific, Double-Observer Correction Factors for Elk}

\section{Data Preparation}

We prepared data from detection of elk groups by individual observers as detection events in a mark-releaserecapture analytical setting. We used a closed-capture modeling approach that allowed for individual elk group covariates to influence detection probability (Huggins, 1991). There are two potentially valid approaches to modeling the overall detection probability of each elk group: approach 1 combines both back seat observers into a single observation unit, whereas approach 2 estimates detection probabilities for each observer separately. Appendix 2 presents details of the analysis that were specific to approach 1, and appendix 3 presents details of the analysis specific to approach 2 . The parsimony of these two modeling approaches cannot be compared directly, but their estimates can be compared.

Individual covariates associated with each elk group may have affected the probability that an observer saw that group. Covariate values were coded so that they could be used in program MARK (White and Burnham, 1999). We made the following transformations for categorical variables: activity was coded with dummy variables ( 1 or 0 ), with bedded coded as a 0 and standing or moving coded as a 1 ; substrate was coded with dummy variables, with grass, herbaceous, and rock together in one class and shrubs as a separate class (no elk groups were observed in trees); vegetative cover was taken as the midpoint of the selected range. If the written data sheets contained missing values for any of these covariates, we listened to the audio recording of the flight for spoken comments about the covariates. If an elk group had "grass" as its substrate, then we assigned any missing values for vegetation cover and height as zero.

If any observer called out about the presence of an elk group before the other crew members had a chance to observe the group, then that group was not included in the doubleobserver analysis.

\section{Model Selection}

The influence of covariates on detection probability was unknown, so we used a model-comparison framework (Burnham and Anderson, 1998) to assess which covariates influenced detection probability. The objects detected in the mark-resight model were elk groups, not individual elk, because only groups are sighted independently. We modeled the probability of detecting elk groups by using the Huggins closed-capture estimator for mark-resight data with individual covariates in program MARK (White and Burnham, 1999). Under modeling approach 1, all models were structured with three capture occasions corresponding to the three possible observers: left front, right front (pilot), and back. Under approach 2, all models were structured with four capture occasions corresponding to the individuals in the helicopter. In all of the candidate models that we tested, we set the recapture probability, $c$, equal to the initial detection probability $(p)$. This setting reflects the explicit assumption of double-observer analyses (Barker, 2008) that each observer's detection records are independent.

Both modeling approaches were designed to estimate the effects of elk position on detection probability. For example, the left-front observer has limited visibility to the right side of the helicopter because the pilot and instrumentation obstruct the view, so we reasoned that models should include potentially different probabilities for the left-front observer, depending on the position of the elk group.

In addition, models potentially included parameters that represented additive effects of other individual covariates that were measured for each elk group. We limited the inclusion of covariates related to the vegetation surroundings of each elk group to no more than two, because the number of observations was not large enough to support a highly parameterized model.

We compared the parsimony of the candidate models by using Akaike's Information Criterion adjusted for small sample size (AICc) (Burnham and Anderson, 1998). We used the most parsimonious of the candidate models to yield the expected detection probabilities for each observer to have detected an elk group with those covariate values. For modeling approach 1 , the expected probability that the left-front observer detects a given group, $i$, is $\hat{p}_{L F, i}$, the expected probability for the right front (pilot) observer is $\hat{p}_{R F, i}$, and the pooled expected probability for the back seat observers is $\hat{p}_{B a c k, i}$. The circumflex (hat) sign over any probability indicates that it is an estimate that has associated estimates of uncertainty. For modeling approach 2 , the expected probabilities $\hat{p}_{L F, i}$ and $\hat{p}_{R F, i}$ are as above, the expected probability for back seat observer Paul Griffin to see a given group, $i$, is $\hat{p}_{P G, i}$, and that for back seat observer Kate Searle is $\hat{p}_{K S, i}$.

\section{Detection Probability and Abundance Estimation}

The parameterized models estimate the probability that a given observer would see a given elk group $(i)$. These probabilities are estimated from a logit link function with beta parameters that interact with measured individual covariate values for each elk group $(i)$. Under modeling approach 1 , the estimate for overall probability of detecting an elk group $i$ is one minus the probability that all three observers missed it, as in equation 1.

$$
\hat{p}_{\text {detect }, i}=1-\left(1-\hat{p}_{L F, i}\right) *\left(1-\hat{p}_{R F, i}\right) *\left(1-\hat{p}_{B a c k, i}\right)
$$


Similarly, under modeling approach 2 , the overall probability of detecting an elk group $i$ is given by equation 2 .

$\hat{p}_{\text {detect }, i}=1-\left(1-\hat{p}_{L F, i}\right) *\left(1-\hat{p}_{R F, i}\right) *\left(1-\hat{p}_{P G, i}\right) *\left(1-\hat{p}_{K S, i}\right)(2$

The inverse of $\hat{p}_{\text {detect }, i}$ for a given elk group is the weight of the contribution from that group to the overall estimate of population size (Steinhorst and Samuel, 1989). If a group, $i$, had a nonzero probability $\hat{p}_{\text {detect }, i}$, then $1 / \hat{p}_{\text {detect }, i}$ is the weight of that group, plus the weight of a corresponding number of unseen groups like it that it represents. In this sense, $1 / \hat{p}_{\text {detect }, i}$ is the group-specific double-observer correction factor. We used no correction factor for the groups that we omitted from double-observer analysis. If $N_{\text {observed }, i}$ is the number of animals counted in group $i$, and $n$ is the number of observed groups, then the estimated number of elk in the surveyed area, $\hat{N}_{\text {available }}$, is the sum of the products of observed group size divided by the group-specific overall detection probability (equation 3).

$$
\hat{N}_{\text {available }}=\sum_{i=0}^{n} \frac{N_{\text {observed }, i}}{\hat{p}_{\text {detect }, i}}
$$

Thus, $\hat{N}_{\text {available }}$ is an estimate of the number of elk that were seen plus those that were not seen even though they were potentially visible. The value of $\hat{N}_{\text {available }}$ does not account for elk that were outside of the surveyed area.

Uncertainty around the detection probability estimates is a result of sampling variance, model selection uncertainty, and process variance. In these surveys, the surveyed area was sampled only once, so it is not possible to estimate sampling variance. Model selection uncertainty arises when two or more of the competing models that describe detection probabilities have comparably parsimonious fit to the data. Comparable parsimony is indicated by differences in AIC $c$ scores of less than 2.0 (Burnham and Anderson, 1998), so we used model averaging to incorporate model selection uncertainty in our parametric estimates if there was a model that had an AIC $c$ score of less than 2.0, compared to the top ranked model. In model averaging, parametric estimates from all candidate models were weighted, based on Akaike weight (Burnham and Anderson, 1998). If no other model had an AIC $c$ score less than 2.0, compared to the top model, then we considered model selection uncertainty to be minimal, and we assessed parameter estimates by using only the top ranked model.

Because the process being estimated by our analysis was the process of detecting elk groups, process variance in this context is variation around the expectation of detection probability. The 95-percent confidence intervals (C.I.) for elk abundance in the surveyed area, $\hat{N}_{\text {available }}$, are a function of the group-specific variance estimates for each observer's group-specific detection probability, as well as any model uncertainty incorporated in model averaging. Our use of two parallel modeling approaches allowed us to compare the effect of modeling approach on estimated abundance.

\section{Results}

\section{Environmental Conditions, Survey Coverage, and Flight Speed}

We conducted surveys during three flight segments (fig. 1). Each flight segment included ferry time to and from surveyed areas and time on survey when animals were counted. Areas surveyed during different flight segments did not overlap.

March 19, 2009, temperatures at the NPS weather station on Santa Rosa Island (395-meter [m] elevation above sea level) were $17^{\circ} \mathrm{C}$ at 8 a.m., $20^{\circ} \mathrm{C}$ at noon, and $16^{\circ} \mathrm{C}$ at 4 p.m.; winds at the weather station did not exceed 14 kilometers per hour ( $\mathrm{km} / \mathrm{hr}$ ) (Western Regional Climate Center, 2009). Weather on Santa Rosa Island on March 19, 2009, was mostly clear but with thick fog developing over coastal areas of the island at different times of day. Fog prevented us from surveying the southern and western coastal margin of the island in zones 3,4 , and 5 . The approximate area that was not surveyed at all, because of fog, was about 9 square kilometers $\left(\mathrm{km}^{2}\right)$, or about 4 percent of the island. Also, a large area in the north of zone 1 was in fog much of the day; when this area was surveyed late in the day, the survey was conducted at high speed and with relatively poor coverage because fuel and flight time were limited.

March 20, 2009, was densely foggy over much of the island. Conditions were not suitable for safe flight, and fog was predicted to worsen on March 21. The decision was made to not conduct the second day of survey, so we were unable to meet the objective of recording double-observer data for deer.

The total distance flown on the survey was 628 kilometers $(\mathrm{km})$, at an average ground speed of $84 \mathrm{~km} / \mathrm{hr}$. The average search effort per unit area was 2.1 minutes per square kilometer $\left(\mathrm{min} / \mathrm{km}^{2}\right)$, which was greater than the $1.3 \mathrm{~min} / \mathrm{km}^{2}$ reported for elk surveys in 2007 but comparable to the 2.3 $\mathrm{min} / \mathrm{km}^{2}$ recorded for deer surveys in 2007 (P.J. Gogan, unpub. data). The ratio of flight-path length to survey-zone area was lowest for zone 5 and greatest for zones 1 and 6 (table 1).

\section{Raw Counts of Deer and Elk}

We saw 101 elk and 120 deer during the first flight segment, 191 elk and 142 deer during the second, and 169 elk and 172 deer during the third (figs. 2 and 3). The number of deer and elk groups and individual animals seen in each survey zone is presented in table 2 .

Observations of 11 deer groups are not included in counts presented in this report because their location was too close to another previous deer group or because the observers did not clearly distinguish two groups seen simultaneously; however, 
in four cases when two deer groups were noted at close points in time, the two groups were recorded separately because the observers' cockpit conversation included evidence that the groups were separate, based on the group position in the landscape.

\section{Estimated Abundance of Elk}

The following is a tally of which groups were seen by which observers; this tally should not be used to derive detection probabilities directly because it overlooks the effects of covariates on detection probabilities. Sixty-eight groups were seen by one or more left-side observers; 40 were seen by both left-side observers; 14 were seen by the left-front observer only; and 14 were seen by the left-rear observer only. The left-front observer detected 7 of 15 elk groups that were only on the right side of the helicopter. Of those same 15 groups, 4 were seen by both right-side observers; 9 were seen by the right-rear observer but missed by the pilot; 1 was seen by the pilot but not by the right-rear observer, and 1 was seen only by the left-front observer. In evaluating the acuity of individual observers independently of their seating position (observers moved around) we determined that observer KS detected 33 out of 37 elk groups that were on the same side of the helicopter and seen by one or more observers, whereas observer PG detected 34 out of 46 elk groups that were on the same side of the helicopter and seen by one or more observers.

Modeling approach 1 led to an estimate of 482.7 elk in the survey zone, with a 95-percent C.I. from 478.6 to 523.9 elk. Modeling approach 2 led to an estimate of 488.6 elk in the survey zone, with a 95-percent confidence interval from 471.2 to $535.3 \mathrm{elk}$.

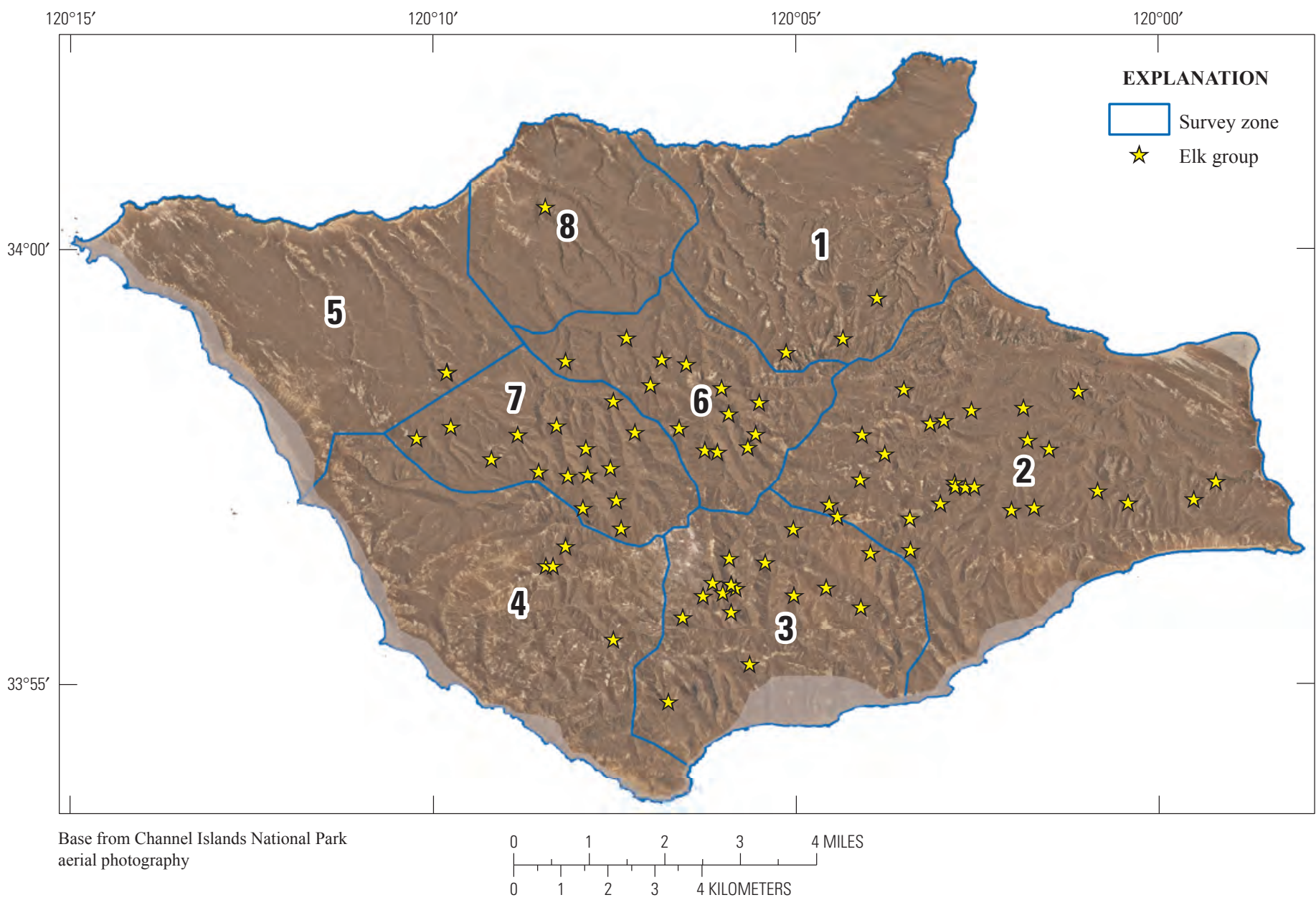

Figure 2. Locations of 81 elk groups (461 elk) observed on Santa Rosa Island on March 19, 2009. 


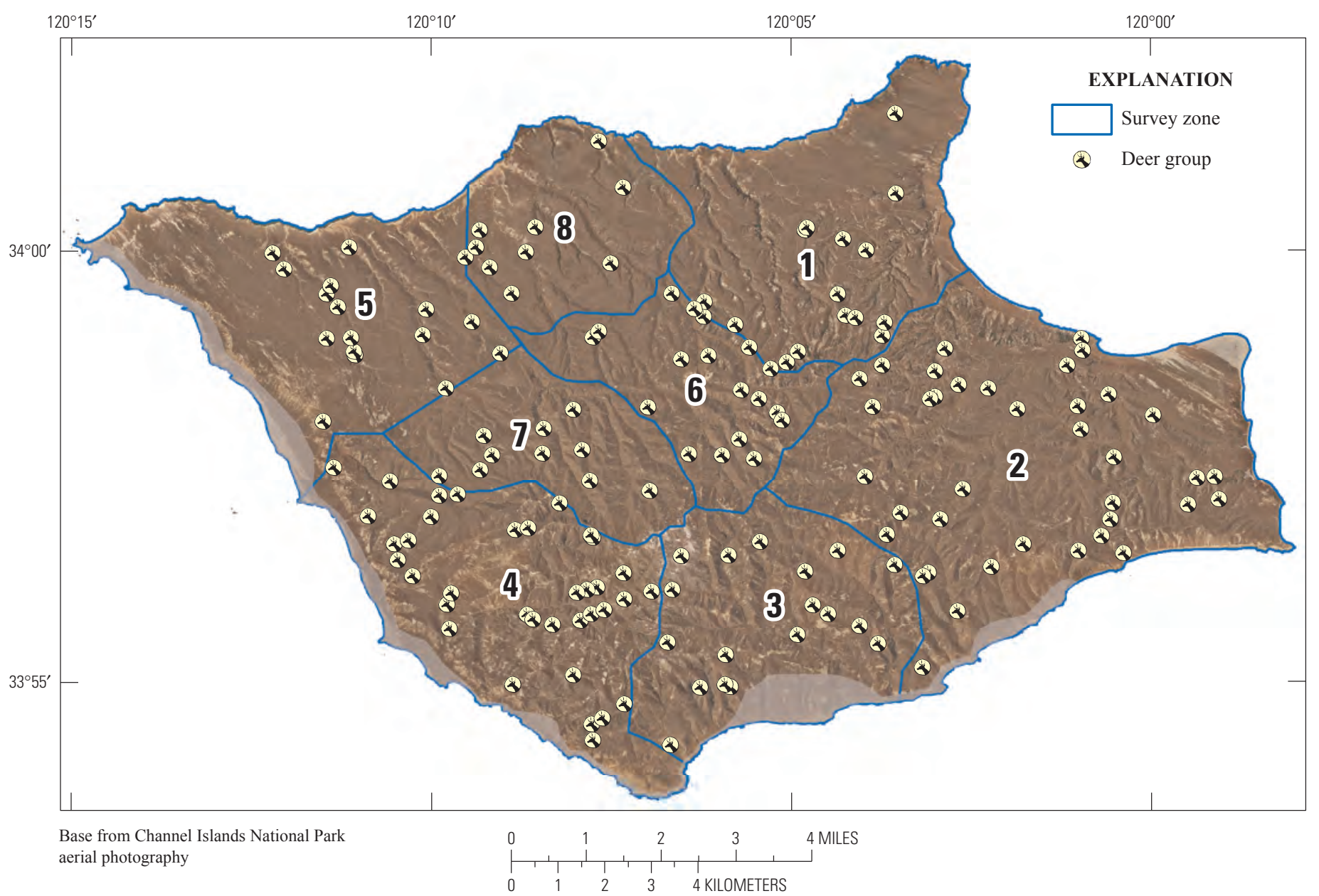

Figure 3. Locations of 161 deer groups (434 deer) observed on Santa Rosa Island on March 19, 2009.

\section{Discussion}

For those areas that were surveyed, this survey appeared to have search effort that was comparable to past surveys. For example, P.J. Gogan (unpub. data) estimated that there was an average of $1.3 \mathrm{~min} / \mathrm{km}^{2}$ for the elk survey of December 12 , 2007 , and $2.3 \mathrm{~min} / \mathrm{km}^{2}$ for the deer survey of December 12 and 13, 2007. Our average search intensity on March 19, 2009, was $2.1 \mathrm{~min} / \mathrm{km}^{2}$ (table 1 ).

Along with the helicopter survey counts of 2008 for Santa Rosa Island, our raw observation results confirm that, for helicopter-based surveys, detection probability of both deer and elk is variable. We counted more deer than were counted in December 2008. Conversely, we counted fewer elk than were counted in December 2008. Apparently, neither the 2008 nor the March 2009 survey found all the animals present; this result alone indicates that detection probability for both species is variable.
We were unable to collect double-observer observation data for deer because fog prevented us from surveying on March 20, 2009, but we did count 434 deer on the portion of the island that was surveyed on March 19, 2009. Vail (2008) assumed that the 424 deer seen in the December 2008 survey represented all deer on the island. One hundred and seventeen deer were shot after the 2008 survey, which led Vail (2008) to state that there were less than 315 deer remaining on the island at the end of 2008. Given the December 2008 count data and the culling data, the March 2009 count was higher than expected, which suggests that detection probability for deer was higher in March 2009 than in December 2008. Reasons for a variable probability are not clear but could be related to seasonal changes in forage availability, deer foraging behavior, or seasonal variations in deer behavior related to hunting seasons that were close to the December survey. We think it is unlikely that the probability of detecting deer on Santa Rosa Island would be 1.0 at any time considering that it has been 
Table 1. Flight speed and an index of survey coverage tabulated by zone.

[Within each survey zone, flight-path distance is the distance of the helicopter's path while on survey, ignoring altitudinal distance (that is, distance is calculated only in the horizontal plane). The index of survey coverage is the ratio of flight-path distance in each zone to zone area. Survey flight speed is the average ground speed of the helicopter, calculated with the flight-path distance in each zone and the time in each zone. $\mathrm{km}^{2}$, square kilometers; $\mathrm{km}$ flown $/ \mathrm{km}^{2}$, kilometers flown per square kilometer; $\mathrm{min} / \mathrm{km}^{2}$, minutes per square kilometer; $\mathrm{km} / \mathrm{hr}$, kilometers per hour]

\begin{tabular}{ccccccc}
\hline $\begin{array}{c}\text { Survey } \\
\text { zone }\end{array}$ & $\begin{array}{c}\text { Area } \\
\left(\mathbf{k m}^{2}\right)\end{array}$ & $\begin{array}{c}\text { Flight path } \\
(\mathbf{k m})\end{array}$ & $\begin{array}{c}\text { Index of survey coverage } \\
(\mathbf{k m} \text { flown//km² }\end{array}$ & $\begin{array}{c}\text { Survey time } \\
(\mathbf{m i n u t e s})\end{array}$ & $\begin{array}{c}\text { Search effort } \\
\left(\mathbf{m i n} / \mathbf{k m}^{2}\right)\end{array}$ & $\begin{array}{c}\text { Survey flight speed } \\
(\mathbf{k m} / \mathbf{h r})\end{array}$ \\
\hline 1 & 28.8 & 116.02 & 4.0 & 71 & 2.5 & 98.1 \\
2 & 53.0 & 188.91 & 3.6 & 139 & 2.6 & 81.6 \\
3 & 24.7 & 64.30 & 2.6 & 48 & 1.9 & 80.7 \\
4 & 31.5 & 73.79 & 2.3 & 49 & 1.6 & 89.7 \\
5 & 30.2 & 42.87 & 1.4 & 30 & 1.0 & 86.5 \\
6 & 15.2 & 58.70 & 3.9 & 37 & 2.4 & 95.2 \\
7 & 15.2 & 44.03 & 2.9 & 52 & 3.4 & 50.7 \\
8 & 16.2 & 40.35 & 2.5 & 23 & 1.4 & 104.3 \\
\hline Total & $\mathbf{2 1 4 . 8}$ & $\mathbf{6 2 8 . 9 7}$ & $\mathbf{2 . 9}$ & $\mathbf{4 4 9}$ & $\mathbf{2 . 1}$ & $\mathbf{8 4 . 0}$ \\
\hline
\end{tabular}

Table 2. Number of observed ungulate groups by survey zone.

["Group" is one or more individuals. Additional columns present the total number of deer or elk seen in each zone and the number of deer or elk seen per square kilometer $\left.\left(\mathrm{km}^{2}\right)\right]$

\begin{tabular}{|c|c|c|c|c|c|c|}
\hline Zone & Elk groups seen & Elk seen & $\begin{array}{l}\text { Elk seen } \\
(\text { per km²) }\end{array}$ & Deer groups seen & Deer seen & $\begin{array}{c}\text { Deer seen } \\
\left(\text { per } \mathbf{k m}^{2}\right)\end{array}$ \\
\hline 1 & 3 & 3 & 0.1 & 18 & 66 & 2.3 \\
\hline 2 & 26 & 100 & 1.9 & 38 & 92 & 1.7 \\
\hline 3 & 17 & 95 & 3.8 & 17 & 35 & 1.4 \\
\hline 4 & 4 & 72 & 2.3 & 36 & 96 & 3.0 \\
\hline 5 & 2 & 7 & 0.2 & 17 & 42 & 1.4 \\
\hline 6 & 13 & 81 & 5.3 & 15 & 48 & 3.2 \\
\hline 7 & 15 & 101 & 6.6 & 11 & 35 & 2.3 \\
\hline 8 & 1 & 2 & 0.1 & 9 & 20 & 1.2 \\
\hline Total & 81 & 461 & 1.9 & 161 & 434 & 1.79 \\
\hline
\end{tabular}

found to be less than 1.0 in the majority of studies in other habitats, including scrub and grassland habitats.

Similarly for elk, estimated detection probability was less than 1.0. One indication of this detection probability comes from discrepancies in raw counts. We detected $461 \mathrm{elk}$, which were fewer than the 554 elk that were calculated to be remaining on Santa Rosa Island, based on the number of elk seen on the 2008 flight (686) minus the number killed after that survey (132) (Timothy Vail, written commun., 2008). Other evidence indicating that not every elk group was seen comes from two complementary approaches to double-observer analysis that led to per-observer estimates of detection probability. Based on those analyses, approximately 5 percent of the elk groups that were present in the surveyed area were not detected by any observer. Both approaches indicated that elk groups were most likely to be missed if they were in shrub cover, on the right side of the flight line, or if group size was small. Group size and vegetative cover are important group-specific covariates in many sightability models (McCorquodale, 2001). Even though we used two different approaches to modeling detection probabilities, both approaches led to estimates of elk abundance in the surveyed area, $\hat{N}_{\text {available }}$, that were in very close agreement: 482.7 elk (95-percent C.I. $=478.6-523.9$ elk) or $488.6 \mathrm{elk}$ (95-percent C.I. $=471.2-535.3$ elk). The wider confidence intervals resulting from the latter approach were likely a result of increased variance coming from model averaging over several closely ranked models. Results from both models supported the conclusion that small groups were less likely to 
be detected than large groups and that detection probability for elk groups was affected by the obscuring presence of shrubs and the position of an elk group relative to the flight path. In our case, elk on the left side of the helicopter were more likely to be detected. We attributed this difference to a lower probability that the pilot detected a given elk group, relative to other observers. The pilot was on the right side of the helicopter during all flights.

We reiterate that even the estimated number of elk is likely to be biased low because an unknown number of elk groups could have been located outside the surveyed area or could have been effectively unavailable for detection because of obscuring fog, vegetation, or topography. The survey was fairly exhaustive except where fog prevented any flight along the coastal margins of zones 3, 4, and 5 and where flight speed was exceptionally high in the Carrington area of zone 1 . In the 2007 survey, zones 4 and 5 had the second and third highest recorded elk densities (P.J. Gogan, unpub. data), but no data exist that would indicate what proportion of observed elk groups in 2007 were found along the coastal margins that were not surveyed in March 2009.

Application of the double-observer method likely did account for some proportion of animal groups not detected during the survey. Because the double-observer method uses records of animal groups that are seen, however, this method cannot be used to estimate the proportion of elk that, through their behavior or vegetative cover, remained invisible to survey. Some number of elk and deer being fitted with radio collars could be useful for estimating the fraction of animals that are not seen during helicopter surveys. The results presented in this report underscore the value of the doubleobserver method for estimating ungulate abundance on Santa Rosa Island.

\section{References Cited}

Barker, R.J., 2008, Theory and application of mark-recapture and related techniques to aerial surveys of wildlife: Wildlife Research, v. 35, p. 268-274.

Beyer, H.I., 2006, Hawth's analysis tools, version 3.27, accessed April 15, 2009, at www.spatialecology.com.

Borchers, D.L., Laake, J.L., Southwell, C., and Paxton, C.G.M., 2006, Accomodating unmodeled heterogeneity in double-observer distance sampling surveys: Biometrics, v. 62 , p. $372-378$.

Buckland, S.T., Anderson, D.R., Burnham, K.P., Laake, J.L., Borchers, D.L., and Thomas, L., 2004, Advanced distance sampling - estimating abundance of biological populations: Oxford, Oxford University Press, 414 p.
Burnham, K.P., and Anderson, D.R., 1998, Model selection and inference - a practical information-theoretic approach: New York, Springer-Verlag, 372 p.

Campbell Grant, E.H., Jung, R.E., Nichols, J.D., and Hines, J.E., 2005, Double-observer approach to estimating egg mass abundance of pool-breeding amphibians: Wetlands Ecology and Management, v. 13, p. 305-320.

Caughley, Graeme, 1974, Bias in aerial survey: Journal of Wildlife Management, v. 38, p. 921-933.

Caughley, Graeme, and Grice, David, 1982, A correction factor for counting emus from the air and its application to counts in Western Australia: Australian Wildlife Research, v. 9, p. 253-259.

Cogan, R.D., and Diefenbach, D.R., 1998, Effect of undercounting and model selection on sightability-adjustment estimator for elk: Journal of Wildlife Management, v. 62, p. 269-279.

Crête, Michel, Vandal, D. , Rivest, L.P., and Potvin, Francois, 1991, Double-counts in aerial surveys to estimate polar bear numbers during the ice-free period: Arctic, v. 44, p. $275-278$.

ESRI, 2008, ArcMap version 9.3.: Redlands, Calif.

Evans Mack, Diane, Raphael, M.G., and Laake, J.L., 2002, Probability of detecting marbled murrelets at sea-effects of single versus paired observers: Journal of Wildlife Management, v. 66, p. 865-873.

Graham, Alistair, and Bell, Richard, 1989, Investigating observer bias in aerial survey by simultaneous doublecounts: Journal of Wildlife Management, v. 53, p. 1009-1016.

Huggins, R.M., 1991, Some practical aspects of a conditional likelihood approach to capture experiments: Biometrics, v. 47, p. $725-732$.

Lubow, B.C., and Ransom, J.I., 2007, Aerial population estimates of wild horses (Equus caballus) in the Adobe Town and Salt Wells Creek Herd Management Areas using an integrated simultaneous double-count and sightability bias correction technique: U.S. Geological Survey Open-File Report 2007-1274, 13 p.

MacKenzie, D.I., Nichols, J.D., Royle, J.A., Pollock, K.H., Bailey, L.L., and Hines, J.E., 2006, Occupancy estimation and modeling; inferring patterns and dynamics of species occurrence: San Diego, Calif., Academic Press, 324 p. 
Marsh, Helene, and Sinclair, D.F., 1989, Correcting for visibility bias in strip transect aerial surveys of aquatic fauna: Journal of Wildlife Management, v. 53, p. 1017-1024.

McCorquodale, S.M., 2001, Sex-specific bias in helicopter surveys of elk - sightability and dispersion effects: Journal of Wildlife Management, v. 65, p. 216-225.

Otten, M.R., Haufler, J.B., Winterstein, S.R., and Bender, L.C., 1993, An aerial censusing procedure for elk in Michigan: Journal of Wildlife Management, v. 21, p. 73-80.

Pollock, K.H., Marsh, H.D., Lawler, I.R., and Alldredge, M.W., 2006, Estimating animal abundance in heterogeneous environments - an application to aerial surveys for dugongs: Journal of Wildlife Management, v. 70, p. 255-262.

Samuel, M.D., Garton, E.O., Schlegel, M.W., and Carson, R.G., 1987, Visibility bias during aerial surveys of elk in Northcentral Idaho: Journal of Wildlife Management, v. 51, p. 622-630.

Schoenecker, Kate, Lubow, Bruce, Ziegenfuss, Linda, and Mao, Julie, 2006, 2005 Annual progress report—elk and bison grazing ecology in the Great Sand Dunes Complex of Lands: U.S. Geological Survey Open-File Report 2006$1267,45 \mathrm{p}$.

Seber, G.A.F., 1982, The estimation of animal abundance and related parameters ( $2 \mathrm{~d}$ ed.): New York, Macmillan, $654 \mathrm{p}$.

Steinhorst, R.K., and Samuel, M.D., 1989, Sightability adjustment methods for aerial survey of wildlife populations: Biometrics, v. 45, p. 415-425.
Swenson, J.E., 1982, Effects of hunting on habitat use by mule deer on mixed-grass prairie in Montana: Wildlife Society Bulletin, v. 10, p. 115-120.

Thompson, W.L., White, G.C., and Gowan, C., 1998, Monitoring vertebrate populations: San Diego, Calif., Academic Press, $365 \mathrm{p}$.

Unsworth, J.W., Leban, F.A., Leptich, D.J., Garton, E.O., and Zager, P., 1994, Aerial survey-user's manual with practical tips for designing and conducting aerial big game surveys: Boise, Idaho Department of Fish and Game, np.

U.S. Fish and Wildlife Service, 2000, Thirteen plant taxa from the Northern Channel Islands recovery plan: Portland, Oregon. 94 p. http://ecos.fws.gov/docs/recovery_plan/000926. $p d f$

Western Regional Climate Center, 2009, accessed March 19, 2009, at www.wrcc.dri.edu

White, G.C., Anderson, D.R., Burnham, K.P., and Otis, D.L., 1978, Capture-recapture and removal methods for sampling closed populations: Los Alamos, New Mexico, Los Alamos National Laboratory LA-8787-NERP, 235 p.

White, G.C., and Burnham, K.P., 1999, Program MARK-survival estimation from population of marked animals: Bird Study, v. 46, p. 120-138.

Williams, B.K., Nichols, J.D., and Conroy, M.J., 2002, Analysis and management of animal populations: San Diego, Calif., Academic Press, 817 p. 



\section{Appendixes}


Appendix 1. Replicas of Flight Data Forms Used by Participants in Aerial Surveys, March 2009. Abbreviations used on forms are given in "Instructions for flight survey form."

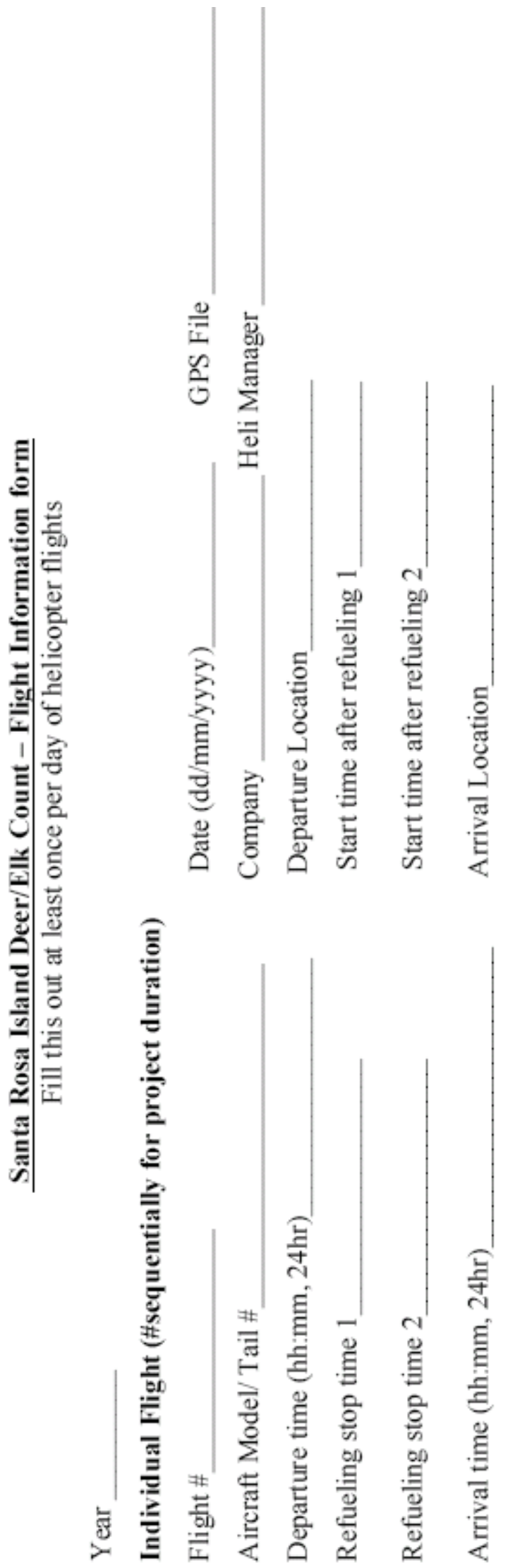


Appendixes

15

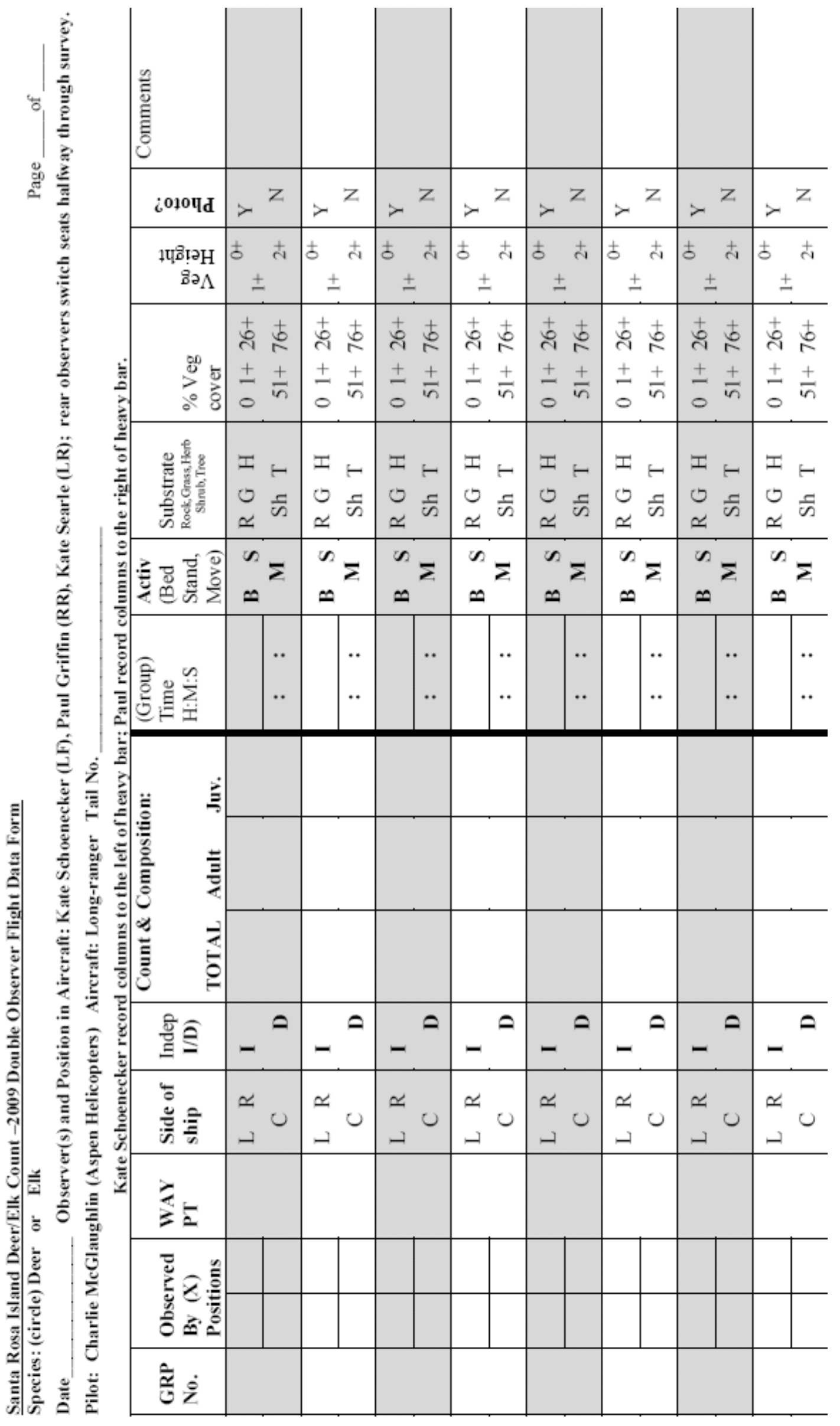




\section{Instructions for flight survey form:}

Date $(\mathrm{dd} / \mathrm{mm} /$ yyyy $)$

Observer: Circle your name and position

Comments: Write other notes in general here

Time: 24-hour time when over group

GRP No.: this is the unique group observation number; one should be given per group.

Observed by: mark with an " $X$ " who saw that group. The four boxes are oriented the same as the passengers in the helicopter, with the top row being for the front seat observers, bottom row for back.

Side of Ship: This is very important: circle " $C$ " (center) if the animal group was straight in front at all times, and passed only under skids (not available for rear seat to have seen). $\mathrm{L}=$ left. $\mathrm{R}=$ right.

Ind Dep I/D: I=All observers saw animal independent of cues from other crew. $\mathrm{D}=\mathrm{An}$ observer saw animal only after subtle (or not-so-subtle) cues. Default is Independent, unless noted.

Activity: (Pick this based on the most active member of the group, when they were first seen): $\mathrm{B}=$ bedded $\mathrm{S}=$ standing, $\mathrm{M}=$ moving

Substrate (Pick this based on the majority of the group): $\mathrm{R}=$ rock, $\mathrm{G}=$ grass, $\mathrm{H}=$ herbaceous, $\mathrm{Sh}=$ shrub, $\mathrm{T}=$ trees.

\%Veg Cover; \%Veg cover (trees \& tall shrubs) that obstruct or screen the view of animals, based on area including entire animal group $+10 \mathrm{~m}$ buffer.

Veg Height: Height of vegetation immediately around the group. $0+$ means from zero to $<1 \mathrm{~m}$ tall; $1+$ means from 1 to $<2 \mathrm{~m}$ tall; $2+$ means $>2 \mathrm{~m}$ tall.

Photo: Circle "Y" (yes) if a photo was taken. Default is "N" (no).

\section{Appendix 2. Modeling Approach 1: Back-Seat Observations Pooled}

\section{Data Preparation}

The first approach to data analysis was structured beforehand to estimate a single-pooled detection probability for back-seat observers. Back-seat observers generally have fields of view that do not overlap. This approach may be justified in cases where the number of observations is too few to parameterize individual estimates of detection probability for back-seat observers separately.
Observations from the left-front observer (LF) were treated as one column in the capture history file. Observations from the pilot sitting in the right front seat (RF) formed the second column in the capture history. Observations from the back-seat observers (Back) were pooled to form the third column in the capture history. If either Back observer observed an elk group before being cued in by a front-seat observer, then the Back data column was coded as a "1," and if neither Back observer saw an elk group, then it was coded for the Back as a " 0 ." The motivation for pooling Back detections into a single column in the capture history is that the Back observers were each looking out of only one side of the helicopter, so collectively they formed a single observer viewing both sides of the helicopter.

We created a dummy variable called "Right," which had a value of one if the position of an elk group relative to the flight path was such that the entire elk group was only on the right side of the flight path. If one or more elk in a group was located on the left side of the flight path, then the value of "Right" was zero. If an elk group was located only directly under the center of the flight path, then we considered that it was not possible for the Back to see that group, so we did not include such groups in the double-observer analysis.

\section{Model Selection}

We structured 31 models to fit to the observed elk group data. All models included three separate intercept parameters: one for LF, one for RF, and one for Back. The sighting probability of the front-seat observers could have been strongly influenced by the position of the elk group, relative to the flight line. As such, models that included a parameter to designate if the elk group was only on the right side of the helicopter led to estimates for the probabilities shown in table A2-1.

We did not know beforehand whether the pilot was influenced by effects of covariates in the same way as the observers whose mission was strictly to search for ungulates; therefore, the covariates (table A2-2) considered in competing model structures were modeled as either influencing all observers or only the LF and Back.

\section{Detection Probability and Abundance Estimation}

We ran the top-ranked model with covariate values corresponding to those of each observed elk group in program MARK to yield group-specific estimates of the expected probability that the left-front observer detects a given group, $i, \hat{p}_{L F, i}$, the expected probability for the right front (pilot) observer detects a given group is $\hat{p}_{R F, i}$, and the pooled expected probability for the back seat observers detecting a group is $\hat{p}_{B a c k, i}$, along with standard error estimates for each of these parameters. The circumflex (hat) sign over any probability indicates that it is an estimate that has associated estimates of uncertainty. The variance for the overall probability of 
Table A2-1. Table of probabilities estimated in the modeling approach with back-seat observations pooled.

[These probabilities can also be affected by many individual covariates, but the position of the elk group (left or right) relative to the flight path of the helicopter is centrally important. Elk groups that passed only under the center of the helicopter are not included in this modeling approach. In this table, $\mathrm{p}(\mathrm{LF} \mid \mathrm{Left})$ means the probability that the left front observer detected an elk group, given that the elk group was on the left side of the helicopter's flight path; $\mathrm{p}(\mathrm{Back})$ means the probability that one or more of the back seat observers detected the elk group]

\begin{tabular}{cccc}
\hline Elk Position & Left Front & Right Front & Back \\
\hline Left Side & $\mathrm{p}(\mathrm{LF} \mid$ Left $)$ & $\mathrm{p}(\mathrm{RF} \mid$ Left $)$ & $\mathrm{p}($ Back $)$ \\
Right Side & $\mathrm{p}(\mathrm{LF} \mid$ Right $)$ & $\mathrm{p}(\mathrm{RF} \mid$ Right $)$ & $\mathrm{p}($ Back $)$ \\
\hline
\end{tabular}

group $i$ having been detected, $\operatorname{Var}\left(\hat{p}_{\text {detect }, i}\right)$, was calculated based on the delta method, with an assumption of no covariance (equation 4).

$$
\begin{aligned}
\operatorname{Var}\left(\hat{p}_{\text {detect }, i}\right)= & \hat{p}_{L F, i} * \operatorname{Var}\left(\hat{p}_{R F, i}\right) * \operatorname{Var}\left(\hat{p}_{B a c k, i}\right) \\
& +\hat{p}_{R F, i} * \operatorname{Var}\left(\hat{p}_{L F, i}\right) * \operatorname{Var}\left(\hat{p}_{B a c k, i}\right) \\
& +\hat{p}_{B a c k, i} * \operatorname{Var}\left(\hat{p}_{R F, i}\right) * \operatorname{Var}\left(\hat{p}_{L F, i}\right)
\end{aligned}
$$

The standard error of $\hat{p}_{\text {detect, } i}$ is given by the square root of $\operatorname{Var}\left(\hat{p}_{\text {detect, } i}\right)$. The 95-percent confidence interval for the group-specific estimate of $\hat{p}_{\text {detect }, i}$ was estimated as $\hat{p}_{\text {detect, }, i} \pm 1.96$ standard error (S.E.) $\left(\hat{p}_{\text {detect, } i}\right)$. In this calculation, we limited $\hat{p}_{\text {detect }, i}$ at a maximum value of one. The 95-percent confidence intervals for the group-specific correction factors were the inverse of the upper and lower $\hat{p}_{\text {detect }, i}$ estimates for the 95 -percent confidence interval. The 95-percent confidence interval of upper and lower limits of group $i$ 's contribution to the overall estimate of elk abundance, $\hat{N}_{\text {available }}$, was given by the upper and lower limits of the group-specific correction factor multiplied by the observed group size of group $i$.

\section{Estimated Abundance of Elk}

Out of the 81 total elk groups observed, 77 provided data that were useful for analysis of double-observer detection probabilities. We did not attempt to estimate double-observer correction factors for two of the 81 elk-group observations that were at the center of the flight line, directly underneath the helicopter; these were not visible from the back seat. We also did not attempt to estimate double-observer correction factors for two more elk groups for which the pilot alerted the Back to their existence; again, an alert from the pilot prevented the Back from having an opportunity to see or not see the elk groups independently. Because Back observers are pooled, all the 77 remaining elk groups could potentially have been observed by all the observers.

Of the 31 candidate models compared against the observed data, the model with the most parsimonious fit was one that included additive effects for the covariates Right_LF, Right_RF, GroupSize_a, and Shrub_a. We refer to this as the highest ranked model. The strong relative support for the highest ranked model is indicated by the Akaike's Information Criterion adjusted for small sample size (AICc) (Burnham and Anderson, 1998) which was 3.8 lower than any other candidate model, and the associated AIC $c$ weight, which was 0.818 . Because this model had high model weight, we did not use model averaging in any parameter estimates.

The structure of the highest ranked model, and the associated parameter estimates (table A2-3), mean that these data had highest support for a model in which the left-front observer had a lower probability of seeing an elk group if it was on the right side of the helicopter, whereas the pilot had a higher probability of seeing such an elk group; the detection probability for the LF and the Back increased as a function of group size but were lower if an elk group was in shrubs.

The logit link functions for detection probability for group $i$ include separate intercept parameters for the LF $(\beta 1)$, RF ( $\beta 2$ ), and Back ( $\beta 3$ ). Parameters $\beta 4$ and $\beta 5$ represent the influence of the elk group's position on the LF and RF observers. LF and Back detection probabilities are increased by the product of $\beta 6$ and Group Size for group $i$, while LF and Back detection probabilities are lowered if the group was in shrub cover. Equations 5, 6, and 7 express the detection probabilities for LF, RF, and Back. 


$$
\begin{gathered}
\hat{p}_{L F, i}=\frac{e^{(\beta 1+\beta 4 * \text { Right }, i+\beta 6 * \text { GroupSize }, i+\beta 7 * \text { Shrub }, i)}}{\left(1+e^{(\beta 1+\beta 4 * \text { Right }, i+\beta 6 * \text { GroupSize }, i+\beta 7 * \text { Shrub }, i)}\right)} \\
\hat{p}_{R F, i}=\frac{e^{(\beta 2+\beta 5 * \text { Right }, i)}}{\left(1+e^{(\beta 2+\beta 5 * \text { Right }, i)}\right)} \\
\hat{p}_{\text {Back }, i}=\frac{e^{(\beta 3+\beta 6 * \text { GroupSize }, i+\beta 7 * \text { Shrub }, i)}}{\left(1+e^{(\beta 3+\beta 6 * \text { GroupSize }, i+\beta 7 * \text { Shrub }, i)}\right)}
\end{gathered}
$$

For the 77 elk groups for which we estimated $\hat{p}_{\text {detect }}$, the median expected value for $\hat{p}_{\text {detect }}$ was 0.977 (range $=0.668$, 1.0). Application of group-specific double-observer correction factors (table A2-4) to the 77 groups that were included in the modeling analysis yielded an expected estimate of 474.7 elk. To that we added eight elk from the four groups that were withheld from the double-observer analysis, yielding a total estimate for $\hat{N}_{\text {available }}(482.7 \mathrm{elk})$. The expected estimate is 21.7 elk greater than the observed number of 461 animals. The 95-percent confidence interval around $\hat{N}_{\text {available }}$ is from 478.6 to 523.9 elk. Based on this analysis, we estimate that we saw 95.5 percent of the elk in the surveyed area.

Table A2-2. List of covariates that were potentially included in the modeling approach with back-seat observations pooled.

[Detection probabilities $\mathrm{p}(\mathrm{LF}), \mathrm{p}(\mathrm{RF}), \mathrm{p}($ Back) are detection probabilities for left front, right front, and back observers, respectively. Veg, vegetation]

\begin{tabular}{cll}
\hline Number & \multicolumn{1}{c}{ Covariate } & \multicolumn{1}{c}{ Covariate Explanation } \\
\hline 1 & $()$. & No covariates influence $\mathrm{p}$ \\
2 & $($ Right_LF) & $\mathrm{p}(\mathrm{LF})$ is uniquely influenced by Right \\
3 & (Right_RF) & $\mathrm{p}(\mathrm{RF})$ is uniquely influenced by Right \\
4 & (Group Size_a) & Group size influences $\mathrm{p}(\mathrm{LF})$ and $\mathrm{p}$ (Back) \\
5 & (Group Size_b) & Group size influences $\mathrm{p}$ for all observers \\
6 & (Veg Cover_a) & Veg cover influences $\mathrm{p}(\mathrm{LF})$ and $\mathrm{p}$ (Back) \\
7 & (Veg Cover_b) & Veg cover influences $\mathrm{p}$ for all observers \\
8 & (Veg Height_a) & Veg height influences $\mathrm{p}(\mathrm{LF})$ and $\mathrm{p}$ (Back) \\
9 & (Veg Height_b) & Veg height influences $\mathrm{p}$ for all observers \\
10 & (Shrub_a) & Presence of Shrubs influences $\mathrm{p}(\mathrm{LF})$ and $\mathrm{p}$ (Back) \\
11 & (Shrub_b) & Presence of Shrubs influences $\mathrm{p}$ for all observers \\
12 & (Activity_a) & Activity (elk not bedded) influences p(LF) and $\mathrm{p}$ (Back) \\
13 & (Activity_b) & Activity (elk not bedded) influences p for all observers \\
\hline
\end{tabular}

Table A2-3. Estimates of the beta ( $\beta$ ) parameters for the logit link function in the highest ranked model for back-seat observations pooled.

[LF, left front observer; RF, right front observer; Back, pair of back seat observers; SE, standard error]

\begin{tabular}{clcc}
\hline Parameter & \multicolumn{1}{c}{ Explanation } & Estimate & SE \\
\hline$\beta 1$ & Intercept for LF & 1.0832452 & 0.5494192 \\
$\beta 2$ & Intercept for RF & -2.7824922 & 0.5197251 \\
$\beta 3$ & Intercept for Back & 1.8212479 & 0.5796759 \\
$\beta 4$ & Effect of Right on LF & -1.7105707 & 0.7349437 \\
$\beta 5$ & Effect of Right on RF & 1.8635444 & 0.7585357 \\
$\beta 6$ & Effect of Group Size on LF and Back & 12.733441 & 6.5390132 \\
$\beta 7$ & Effect of Shrub on LF and Back & -2.0511147 & 0.5476655 \\
\hline
\end{tabular}


Table A2-4. Expected group-specific overall probabilities of detecting an elk group, $\hat{p}_{\text {detect }, i}$, and contributions to total estimates of elk abundance, $\hat{N}_{\text {available }}$, for each observed elk group, based on the top ranked model of the modeling approach with back-seat observers pooled.

[Covariate values for Shrub, Right, and Group Size are listed, as these influence the estimates of probability detection under the highest ranked model. The estimates for $\hat{p}_{\text {detect }, i}$ minus or plus one standard error represent uncertainty in the estimate of $\hat{p}_{\text {detect }, i}$. The sum of each group's contribution to $\hat{N}_{\text {available }}$ is 482.7, with 95-percent confidence interval from 478.6 to $523.9 \mathrm{elk}]$

\begin{tabular}{|c|c|c|c|c|c|c|c|}
\hline $\begin{array}{c}\text { Group number, } \\
\qquad i\end{array}$ & Shrub & Right & Group size & $\hat{p}_{\text {detect }, i}$ & $\begin{array}{c}\hat{p}_{\text {detect }, i} \\
+1.96 * \text { SE }\end{array}$ & $\begin{array}{c}\hat{p}_{d e t e c t, i} \\
-1.96 * 1 S E\end{array}$ & $\begin{array}{c}\text { Contribution to } \\
\hat{N}_{\text {available }}\end{array}$ \\
\hline 1 & 0 & 0 & 1 & $\left({ }^{1}\right)$ & $\left({ }^{1}\right)$ & $(1)$ & 1.00 \\
\hline 2 & 0 & 0 & 1 & .977 & .997 & .957 & 1.02 \\
\hline 3 & 0 & 1 & 1 & .950 & .995 & .906 & 1.05 \\
\hline 4 & 0 & 1 & 5 & .985 & 1.000 & .917 & 5.08 \\
\hline 5 & 0 & 0 & 4 & .992 & 1.000 & .969 & 4.03 \\
\hline 6 & 0 & 0 & 5 & .995 & 1.000 & .970 & 5.03 \\
\hline 7 & 0 & 0 & 1 & .977 & .997 & .957 & 1.02 \\
\hline 8 & 0 & 0 & 13 & 1.000 & 1.000 & .972 & 13.00 \\
\hline 9 & 0 & 0 & 4 & .992 & 1.000 & .969 & 4.03 \\
\hline 10 & 1 & 0 & 3 & .781 & .789 & .773 & 3.84 \\
\hline 11 & 0 & 0 & 14 & 1.000 & 1.000 & .972 & 14.00 \\
\hline 12 & 0 & 0 & 5 & .995 & 1.000 & .970 & 5.03 \\
\hline 13 & 1 & 0 & 2 & .730 & .736 & .723 & 2.74 \\
\hline 14 & 0 & 0 & 1 & .977 & .997 & .957 & 1.02 \\
\hline 15 & 1 & 1 & 1 & .668 & .675 & .662 & 1.50 \\
\hline 16 & 1 & 0 & 5 & .863 & .874 & .852 & 5.79 \\
\hline 17 & 0 & 0 & 1 & .977 & .997 & .957 & 1.02 \\
\hline 18 & 0 & 0 & 2 & .984 & 1.000 & .962 & 2.03 \\
\hline 19 & 0 & 0 & 1 & .977 & .997 & .957 & 1.02 \\
\hline 20 & 0 & 0 & 4 & .992 & 1.000 & .969 & 4.03 \\
\hline 21 & 1 & 0 & 4 & .826 & .836 & .817 & 4.84 \\
\hline 22 & 0 & 0 & 3 & .989 & 1.000 & .966 & 3.03 \\
\hline 23 & 0 & 1 & 1 & $\left.{ }^{2}\right)$ & $\left({ }^{2}\right)$ & $\left(^{2}\right)$ & 1.00 \\
\hline 24 & 0 & 0 & 3 & .989 & 1.000 & .966 & 3.03 \\
\hline 25 & 1 & 0 & 9 & .959 & .977 & .940 & 9.39 \\
\hline 26 & 1 & 0 & 1 & .678 & .683 & .673 & 1.48 \\
\hline 27 & 1 & 0 & 4 & .826 & .836 & .817 & 4.84 \\
\hline 28 & 1 & 0 & 2 & .730 & .736 & .723 & 2.74 \\
\hline 29 & 0 & 1 & 16 & 1.000 & 1.000 & .893 & 16.00 \\
\hline 30 & 1 & 0 & 4 & .826 & .836 & .817 & 4.84 \\
\hline 31 & 1 & 0 & 3 & $\left({ }^{1}\right)$ & $\left({ }^{1}\right)$ & $\left({ }^{1}\right)$ & 3.00 \\
\hline 32 & 0 & 0 & 1 & .977 & .997 & .957 & 1.02 \\
\hline 33 & 1 & 1 & 1 & .668 & .675 & .662 & 1.50 \\
\hline 34 & 1 & 0 & 3 & .781 & .789 & .773 & 3.84 \\
\hline 35 & 1 & 0 & 4 & .826 & .836 & .817 & 4.84 \\
\hline 36 & 1 & 0 & 6 & .896 & .909 & .883 & 6.70 \\
\hline 37 & 1 & 0 & 2 & .730 & .736 & .723 & 2.74 \\
\hline 38 & 1 & 0 & 2 & .730 & .736 & .723 & 2.74 \\
\hline
\end{tabular}




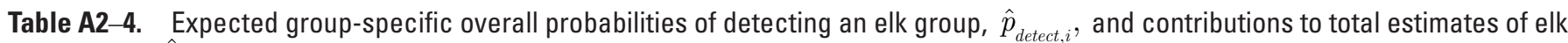
abundance, $\hat{N}_{\text {available }}$, for each observed elk group, based on the top ranked model of the modeling approach with back-seat observers pooled.-Continued

[Covariate values for Shrub, Right, and Group Size are listed, as these influence the estimates of probability detection under the highest ranked model. The estimates for $\hat{p}_{\text {detect }, i}$ minus or plus one standard error represent uncertainty in the estimate of $\hat{p}_{\text {detect, } i}$. The sum of each group's contribution to $\hat{N}_{\text {available }}$ is 482.7, with 95-percent confidence interval from 478.6 to 523.9 elk]

\begin{tabular}{|c|c|c|c|c|c|c|c|}
\hline 39 & 1 & 0 & 5 & 0.863 & 0.874 & 0.852 & 5.79 \\
\hline 40 & 0 & 0 & 3 & .989 & 1.000 & .966 & 3.03 \\
\hline 41 & 0 & 0 & 31 & 1.000 & 1.000 & .971 & 31.00 \\
\hline 42 & 0 & 0 & 3 & .989 & 1.000 & .966 & 3.03 \\
\hline 44 & 0 & 0 & 2 & .984 & 1.000 & .962 & 2.03 \\
\hline 45 & 0 & 0 & 3 & .989 & 1.000 & .966 & 3.03 \\
\hline 46 & 0 & 1 & 3 & .972 & 1.000 & .916 & 3.09 \\
\hline 47 & 1 & 0 & 7 & .923 & .937 & .908 & 7.59 \\
\hline 51 & 1 & 0 & 2 & .730 & .736 & .723 & 2.74 \\
\hline 52 & 0 & 0 & 4 & .992 & 1.000 & .969 & 4.03 \\
\hline 53 & 0 & 0 & 3 & $\left({ }^{2}\right)$ & $\left(^{2}\right)$ & $\left({ }^{2}\right)$ & 3.00 \\
\hline 54 & 1 & 0 & 18 & .999 & 1.000 & .972 & 18.02 \\
\hline 55 & 1 & 1 & 2 & .707 & .715 & .699 & 2.83 \\
\hline 56 & 0 & 0 & 2 & .984 & 1.000 & .962 & 2.03 \\
\hline 57 & 0 & 0 & 1 & .977 & .997 & .957 & 1.02 \\
\hline 58 & 0 & 1 & 2 & .962 & 1.000 & .913 & 2.08 \\
\hline 59 & 1 & 0 & 2 & .730 & .736 & .723 & 2.74 \\
\hline 66 & 1 & 0 & 1 & .678 & .683 & .673 & 1.48 \\
\hline 67 & 0 & 1 & 3 & .972 & 1.000 & .916 & 3.09 \\
\hline 68 & 0 & 0 & 5 & .995 & 1.000 & .970 & 5.03 \\
\hline 69 & 0 & 0 & 5 & .995 & 1.000 & .970 & 5.03 \\
\hline 70 & 0 & 0 & 4 & .992 & 1.000 & .969 & 4.03 \\
\hline 71 & 0 & 0 & 2 & .984 & 1.000 & .962 & 2.03 \\
\hline 72 & 1 & 0 & 4 & .826 & .836 & .817 & 4.84 \\
\hline 73 & 0 & 0 & 21 & 1.000 & 1.000 & .972 & 21.00 \\
\hline 74 & 1 & 0 & 4 & .826 & .836 & .817 & 4.84 \\
\hline 75 & 0 & 0 & 4 & .992 & 1.000 & .969 & 4.03 \\
\hline 76 & 0 & 0 & 3 & .989 & 1.000 & .966 & 3.03 \\
\hline
\end{tabular}


Table A2-4. Expected group-specific overall probabilities of detecting an elk group, $\hat{p}_{\text {detect }, i}$, and contributions to total estimates of elk abundance, $\hat{N}_{\text {available }}$, for each observed elk group, based on the top ranked model of the modeling approach with back-seat observers pooled. - Continued

[Covariate values for Shrub, Right, and Group Size are listed, as these influence the estimates of probability detection under the highest ranked model. The estimates for $\hat{p}_{\text {detect }, i}$ minus or plus one standard error represent uncertainty in the estimate of $\hat{p}_{\text {detect }, i}$. The sum of each group's contribution to $\hat{N}_{\text {available }}$ is 482.7, with 95-percent confidence interval from 478.6 to $523.9 \mathrm{elk}]$

\begin{tabular}{cccrrrrr}
\hline $\begin{array}{c}\text { Group number, } \\
\boldsymbol{i}\end{array}$ & Shrub & Right & Group size & $\hat{p}_{\text {detect, }, i}$ & $\begin{array}{c}\hat{p}_{\text {detect }, i} \\
\mathbf{+ 1 . 9 6 * S E}\end{array}$ & $\begin{array}{c}\hat{p}_{\text {detect }, i} \\
\mathbf{- 1 . 9 6 * 1 S E ~}\end{array}$ & $\begin{array}{c}\text { Contribution to } \\
\hat{\boldsymbol{N}}_{\text {available }}\end{array}$ \\
\hline 77 & 1 & 0 & 2 & 0.730 & 0.736 & 0.723 & 2.74 \\
78 & 0 & 1 & 10 & .998 & 1.000 & .905 & 10.02 \\
79 & 0 & 0 & 9 & .999 & 1.000 & .972 & 9.01 \\
80 & 0 & 1 & 51 & 1.000 & 1.000 & .886 & 51.00 \\
81 & 1 & 1 & 2 & .707 & .715 & .699 & 2.83 \\
\hline Total & & & & & & & $\mathbf{4 8 2 . 6 9}$ \\
\hline
\end{tabular}

${ }^{1}$ No estimates for $\hat{p}_{\text {detect }}$ were attempted for groups 1 and 31, because these observations were omitted from the double-observer analysis; in these cases the elk group was immediately under the center of the flight path.

${ }^{2}$ No estimates for $\hat{p}_{\text {detect }}$ were attempted for groups 23 and 53, because these observations were omitted from the double-observer analysis; in these cases, the pilot (RF) alerted all observers about the elk group before Back had any opportunity to see the group.

\section{Appendix 3. Modeling Approach 2: Separate Detection Probabilities for Each Observer}

\section{Data Preparation}

The second approach to data analysis was structured beforehand to allow for separate detection probabilities for each observer. Variation in observer acuity has been shown to be potentially important in aerial surveys (Pollock and others, 2006), and the double-observer method can be useful for estimating individual observer acuity (Schoenecker and others, 2006; Lubow and Ransom, 2007).

Back seat observers Paul Griffin (PG) and Kate Searle (KS) traded positions between flight segment 1 and flight segment 2, so it was possible to separate effects of seat from effects of individual observer. The elk observation data were prepared for input in program MARK such that each observer's detections were a column in the capture history. Out of 81 observed elk groups, we omitted from the analysis two groups that the pilot called out before other observers had a chance to detect the group, but we retained in the analysis two groups that were directly under the center of the flight path. Akaike's Information Criterion adjusted for small sample size $(\mathrm{AIC} c)$ (Burnham and Anderson, 1998) scores can not be used to compare the parsimony of this modeling approach to that described in appendix 2 because the inputs of the capture history are slightly different.

There were two seating arrangements because observer PG was on the right rear seat for the first flight but on the left rear seat for the second and third flights. Elk group observations were entered in eight "input groups," with four "input groups" per seating arrangement. Each observed elk group was associated with one of the eight "input groups" depending on the elk group position, relative to the line of flight: left, right, center, or both left and right.

\section{Model Selection}

We structured a design matrix for program MARK to represent the potential for each observer's detection probability to vary depending on whether the elk group was on the same side, opposite side, or directly under the center of the helicopter. This basic design matrix led to the estimation of eight intercept parameters in logit link functions for detection probabilities by the left front observer, right front observer, observer Paul Griffin, and observer Kate Searle. These probabilities are denoted $\hat{p}_{L F}, \hat{p}_{R F}, \hat{p}_{P G}$, and $\hat{p}_{K S}$, respectively. If an elk group was positioned along the center or left side of the flight path, then for the purposes of estimating detection probability, the group was considered to be on the same side as the left-front observer. An elk group on the right side of the flight path was considered to be on the opposite side as the left-front observer. Elk on the right were considered to be on the same side as the pilot, but elk on the center or left were considered to be on the pilot's opposite side. Unique intercept parameters were estimated for the rear-seat observers for occasions when an elk was on the same side, but only one parameter was estimated for rear-seat observers detecting elk on the opposite side, and one other parameter was estimated for rear-seat observers detecting elk directly underneath the center of the flight path. 
The candidate suite of models also potentially included the individual covariates recorded in flight, the effects of which were additive across all intercepts in the logit link function. Up to two covariates were included in candidate model structures. In these models, each observer's probability to detect a given elk group was modeled as a logit link function, with the position of the elk group leading to the selection of the observer's intercept, and with additive effects of any covariates included in the model.

\section{Detection Probability and Abundance Estimation}

Eight model structures had differences in $\mathrm{AIC} c$ values $(\triangle \mathrm{AIC} c)$ within about 2 (table $\mathrm{A} 3-1)$, so we model averaged to obtain estimates of the number of elk groups in each of the eight "input groups," along with associated estimates of variance. The highest ranked model was one in which all observers' detection probabilities were decreased by the presence of shrubs and increased if the elk group was standing. Although group size did not directly enter into seven out of eight of the top models, group size apparently correlated with other covariates; evidence for such a correlation is that the group size for observed elk groups (5.69 elk) was higher than the estimated group size for missed elk groups (3.34 elk).

Because no single model was most highly ranked with a difference of more than two $\mathrm{AIC} c$, we model averaged the estimate of the total number of elk groups by using the model averaging function in program MARK. This function sums the estimated total number of elk groups in the output from each model, weighted by the Akaike weight of the model. We estimated the group size of missed groups as the average value of the product of the group-specific double-observer correction factor minus one, multiplied by the observed group size for each group; this is effectively the same as the estimated number of elk missed divided by the estimated number of groups missed. Variance for this estimate was the sum of the squared differences from the mean estimate of missed group size. The estimated number of elk missed, $\mathrm{f}(0)$, was the product of the number of missed groups multiplied by the number of elk per missed group. Variance for $\mathrm{f}(0)$ was estimated by using the delta method with an assumption of no covariance. We assumed a lognormal distribution around the mean expectation to generate 95-percent confidence intervals for $\mathrm{f}(0)$ (Williams and others, 2001). Estimated abundance, $\hat{N}_{\text {available, was the }}$ sum of $\mathrm{f}(0)$ and the observed number of elk, $\mathrm{M}(\mathrm{t}+1)$.

\section{Estimated Abundance of Elk}

Based on this approach, the model-averaged estimated number of elk groups was 87.25 (standard error [S.E.] = 4.34). Adding the two groups that were omitted from the analysis led to a total estimate of 89.25 estimated elk groups. Given that 81 elk groups were actually observed, the estimated number of missed elk groups was 8.25 (S.E. $=4.34$ ). The estimated average group size of elk groups that were missed was 3.34 $($ S.E. $=0.411)$. The estimated number of elk missed, $\mathrm{f}(0)$, was 27.6 (S.E. = 14.9). Assuming lognormal errors, the 95-percent confidence interval for the number of missed elk was from 10.2 to 74.3 . After adding the 461 elk observed, the estimated number of elk in the surveyed area was 488.6 elk, with a 95-percent confidence interval from 471.2 to 535.3 elk. Based on this analysis, 90.1 percent of the elk groups and 94.4 percent of the elk in the surveyed area were seen. 
Table A3-1. Model rankings for the analysis that estimated individual observer detection probability.

[With the exception of model (.), which had only one intercept parameter, all models were structured with eight intercept parameters to reflect each observer's acuity in detecting elk that were on the same side of the helicopter and on the opposite side. Model names refer to the covariates that were included as additive effects in the model, where each "plus" sign indicates an additive effect of the covariate. $\triangle \mathrm{AIC} c$, relative Akaike's Information Criterion value; $\mathrm{w}_{i}$, Akaike weight]

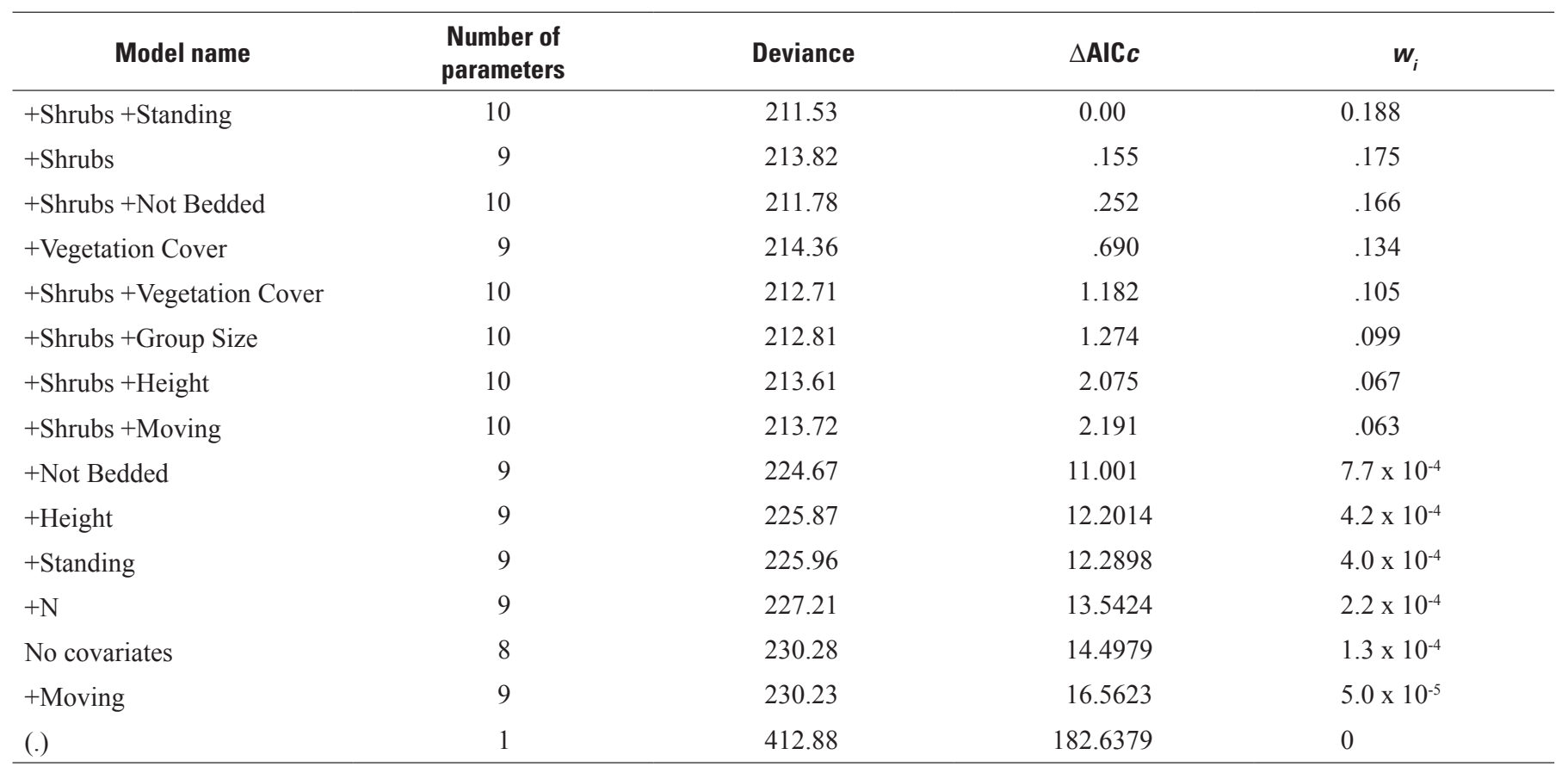


Publishing support provided by:

Denver and Lafayette Publishing Service Centers

For more information concerning this publication, contact:

Director, Northern Rocky Mountain Science Center (NOROCK)

2327 University Way, Suite 2

Bozeman, MT 59715

(406) 994-4293

Or visit the Northern Rocky Mountain Science Center Web site at: http://nrmsc.usgs.gov/ 

